https://helda.helsinki.fi

\title{
Visual performance with small concave and convex displays
}

\section{Mustonen, Terhi}

2015-09-04

Mustonen , T , Kimmel , J , Hakala , J \& Häkkinen , J 2015 , ' Visual performance with small concave and convex displays ' , Human Factors , vol. 57 , no. 6 , pp. 1029-1050 . https://doi.org/10.1177/001872081

http://hdl.handle.net/10138/156537

https://doi.org/10.1177/0018720815570090

acceptedVersion

Downloaded from Helda, University of Helsinki institutional repository.

This is an electronic reprint of the original article.

This reprint may differ from the original in pagination and typographic detail.

Please cite the original version. 
Mustonen, T., Kimmel, J., Hakala, J., \& Häkkinen, J. (2015). Visual performance with small concave and convex displays. Human Factors, 57(6), 1029-1050. doi: 10.1177/0018720815570090

Visual performance with small concave and convex displays

Word count: 9,821

This work was supported by the Finnish Doctoral Program in User-Centered Information

10 Technology and a grant number 3210/31/2010 from the Finnish Technology Development

11 Fund. We thank Marko Raatikka and Heikki Lindroos for programming the experiments,

12 Heikki Pirttinen for his assistance with the DMCU system, and Jari Lipsanen for his advice in 13 statistical analyses. Correspondence corcerning this article should be addressed to Terhi 14 Mustonen, Institute of Behavioural Sciences, P.O. Box 9 (Siltavuorenpenger 1 A), FIN-00014 University of Helsinki, Helsinki, Finland. E-mail: terhi.mustonen@ helsinki.fi; 
VISUAL PERFORMANCE WITH CURVED DISPLAYS

2 Objective: This study aims to investigate how users' visual performance with a small flexible

4 high) of the display curvature.

5 Background: Despite the wide interest in flexible display materials and deformable displays,

6 the potential effects of non-planar display surfaces on human perception and performance

7 have received little attention. This study is the first to demonstrate how curving affects visual

8 performance with an actual flexible display (4.5" AMOLED).

9 Method: In a series of three experiments, we compared the performance with a planar display to the performance with concave and convex display surfaces with low and high curvature

11 magnitudes. Two visual search tasks were employed that required the subject to detect target

12 letters based on their contrast (Experiments 1 and 2) and identity (Experiment 3). Performance was measured as the sensitivity of target detection $\left(d^{\prime}\right)$ and threshold time of the 14 search, respectively.

15 Results: There were similar sensitivities for targets across the curvature variants, but the high-magnitude curvatures resulted in prolonged search times, especially for the convex form.

17 In both of the tasks, performance was dependent on the display location, which was defined 18 as the target's distance from the display center.

19 Conclusion: High curvature magnitudes should be avoided, even in small displays, because 20 large local changes in visual stimuli decrease processing speed outside the central display.

21 Application: The findings have implications for the development of technologies,

22 applications and user interfaces for flexible displays and the design of visual display devices.

23 Keywords: Flexible displays, handheld devices, user performance, visual search, letter 24 identification 
1 Précis: The paper introduces a series of three visual search experiments to investigate how

2 the direction and magnitude of display curvature affect users' visual performance with an 3 actual flexible display.

Visual performance with small concave and convex displays

The appearance and use of future display devices are not constrained by rigid display materials. Rapid advances in thin-film display technology, including the development of electrophoretic ink (E-ink) and organic light-emitting diodes (OLEDs), have already produced the flexible, paper-like displays of eReaders and mobile phones (e.g., LG G Flex, Samsung Galaxy Round). At the same time, these advances have created a base for radical changes in the designs of and interactions with future computing devices. Concepts and prototypes for bendable (Herkenrath, Karrer, \& Borchers, 2008; Kildal, Paasovaara, \& Aaltonen, 2012; Lahey, Girouard, Burleson, \& Vertegaal, 2011; Schwesig, Poupyrev, \& Mori, 2004), rollable (Pillias, Hsu, \& Cubaud, 2013), foldable (Khalilbeigi, Lissermann, Kleine, \& Steimle, 2012), and even self-actuated shape-changing display devices (Roudaut, Karnik, Löchtefeld, \& Subramanian, 2013) have been introduced in recent years, and interaction based on the physical deformation of such devices has risen to the active focus of research (Herkenrath et al., 2008; Khalilbeigi et al., 2012; Kildal et al., 2012; Lahey et al., 2011; Lee et al., 2010; Pillias et al., 2013; Roudaut et al., 2013; Schwesig et al., 2004; Wightman, Ginn, \& Vertegaal, 2011). It has been predicted that ultimately, portable display devices will contain lightweight, high-resolution, multi-touch displays that can be bent, curved, rolled or folded without damaging the display structure. These deformable displays present contents on a malleable surface that can be static (e.g., curved to a form) or changeable (e.g., curved for a certain purpose) via user-initiated or device-initiated deformation, or both (Vertegaal \& Poupyrev, 2008). 
Despite the wide interest in flexible display materials, the potential effects of non-planar

2 display surfaces on human perception and performance have received little attention. In

3 particular, comprehensive data on visual performance with curved small displays is missing.

4 When displayed contents are transferred from planar to non-planar surfaces, it is crucial to

5 understand how this change alters the observer's ability to process visual information. In this

6 study, we investigate visual performance with curved small displays that have static display

7 curvatures. We measure observers' performance in two visual search tasks, which are

8 presented on a flexible active-matrix organic light-emitting diode (AMOLED) display that is

9 bent into five configurations. We aim to compare the performance with curved display

10 surfaces to the performance with a planar display and to clarify how the curvature's direction

11 (i.e., concavity, convexity) and magnitude (i.e., low or high radius size) affect visual

12 perception and the speed of processing of the displayed information. In the following

13 subsections, we introduce characteristics that may differentiate planar and curved displays in

14 regard to visual perception, as well as previous research related to curved portable displays.

\section{Perception of Curved Displays}

15

16

A curved display surface can be formed by bending the display about its vertical or horizontal axis along its short or long side. When combined with the curvature's magnitude, these bending directions generate numerous variations for concave and convex surfaces that may differ in how they affect visual perception. Although current flexible display technologies generally feature wide viewing angles and good contrast (Chen et al., 2003;

Kalyani \& Dhoble, 2012), bending places stress on the display materials, which may degrade the optical characteristics of the display (e.g., brightness and contrast). Such decrements are critical for portable devices that are used in various environments because ambient light alone affects display legibility (Lee, Shieh, Jeng, \& Shen, 2008; Singh, Unni, Solanki, \& Deepak, 2012). 
In addition to optical characteristics, viewing information from a curved display

2 differs from viewing information from a planar display due to changes in display geometry

3 (Fig. 1). First, the orientation of a displayed object relative to the observer's eyes varies

4 slightly based on the direction and magnitude of curvature and the object's location on the

5 display. Second, the depth change along the display surface may result in accommodative

6 responses of the eye. These two features may alter visual perception in a manner that, when

7 combined with changes in the optical characteristics, leads to the deterioration of visual

8 performance.

\section{Local Orientation Change with Curved Displays}

The retinal image of a displayed object changes with the local curvature of the display surface. Here, we describe this change as slant, which refers to the angle between the line of sight and the surface normal to the viewed surface (Fig. 1; for review of coordinate systems, see Norman et al., 2006; Grossman, Wigdor, \& Balakrishnan, 2007). When the display surface and the object slant in relation to the line of sight, the retinal image foreshortens in the direction of the slant (Fig. 1). Typically, such distortions are efficiently corrected by the visual system. For instance, viewing a pictorial image from an oblique line of sight produces a similar percept to perpendicular viewing despite the differential retinal images in these two conditions (Rosinski, Mulholland, Degelman, \& Farber, 1980; Vishwanath, Girshick, \& Banks, 2005). This perceptual invariance requires the availability of binocular and contextual information, however, because uncorrected retinal representation dominates perception that uses monocular viewing or when lacking contextual cues about the picture-plane orientation (Rosinski et al., 1980; Vishwanath et al., 2005; Wallach \& Marshall, 1986). Effective compensation also seems to be limited to slants that are less than $45^{\circ}$ of visual angle (Vishwanath et al., 2005). Furthermore, it appears that the visual system is not sensitive to detecting small changes in local orientations. When observers were asked to judge the 
VISUAL PERFORMANCE WITH CURVED DISPLAYS

1 orientation difference between two local regions of a three-dimensional object, discrimination

2 thresholds range between $4^{\circ}$ and $10^{\circ}$ (Norman et al., 2006).

Despite the amount of research that is devoted to perceptual invariance and the perception of local orientation, only a few studies have considered the effect of orientation change on visual performance. Larson et al. (2000) and Grossman et al. (2007) both investigated the speed of processing rotated text. Larson and colleagues measured naming speed for words that were rotated about the vertical axis, which resulted in a perspective distortion in which the letters on one end of the word were larger than the letters on the other end. They found consistent naming speed for words that were slanted up to $\pm 55^{\circ}$, after which

11 the naming speed decreased with increasing angles of rotation. Similarly, Grossman and 12 colleagues compared recognition times for words that were rotated about the vertical or horizontal axis on a volumetric display. Their results demonstrated that rotation about the horizontal axis had a greater effect on processing speed than rotation about the vertical axis did, but these effects only occurred after $\pm 60^{\circ}$ of rotation. Furthermore, performance was symmetric for rotations about the vertical axis, whereas the words that were rotated about the horizontal axis were read faster when they had positive rotation angles. In sum, previous research suggests that small local changes in displayed stimuli do not alter visual processing, but large orientation changes may affect the processing speed of displayed information.

\section{Depth Change within a Curved Display}

When viewing objects that are presented on a curved display, the distance of each

21 object to the observer's eyes depends on its location due to the depth change along the display surface (Fig. 1). This variation may induce accommodative responses of the eye when the 
1 observer fixates on targets that are in different display locations. The accommodative

2 responses consist of a slow component that is driven by blur in the retinal image and a fast

3 component that is driven by binocular disparity (Campbell \& Westheimer, 1960; Rashbass \&

4 Westheimer, 1961).

The retinal image of an object is sharp when the object appears at the distance to which the eye is focused. A certain extent of retinal defocus can be tolerated without the perception of blur. The range of this area is referred to as the depth-of-focus of the eye (DOF). DOF is roughly \pm 0.3 diopters under optimal viewing conditions (Campbell, 1957), and it varies depending on various internal (e.g., visual acuity, retinal eccentricity) and external (e.g., luminance, contrast; Wang \& Ciuffreda, 2006) factors. Once the object falls outside the DOF, the blurred retinal image triggers the neural commands to accommodate (i.e., to minimize the blur by changing the focal power of the eye). Accommodation takes approximately $300 \mathrm{~ms}$ to initiate and approximately one second to reach a reasonable steady level (Campbell \& Westheimer, 1960). Furthermore, within the DOF accommodation is typically optimized slightly behind the object plane (Gambra, Sawides, Dorronsoro, \& Marcos, 2009). Due to this accommodative lag the corrective responses needed for obtaining information from curved displays may differ between concave and convex surfaces. Another response to the depth change is vergence. It refers to the simultaneous rotation of the two eyes in opposite directions in order to foveate objects while maintaining fused binocular vision. The primary stimulus for vergence is the binocular disparity of the scenes that are seen by the two eyes (i.e., disparity vergence), which triggers convergent (i.e., inward) or divergent (i.e., outward) corrective movements in approximately 160-180 ms (Rashbass \& Westheimer, 1961). Vergence can also be indirectly driven by accommodation via neural crosslinks from the accommodation system (i.e., accommodative vergence), and similarly, accommodation can be driven via vergence-accommodation crosslinks (e.g., 
1 curved displays may initiate accommodation and vergence responses that aid object

2 perception in binocular vision. Objects that are presented at different display locations act as

3 stimuli for these responses (which take time to develop), which, in turn, affects the processing

4 speed of the displayed information.

\section{Research on Curved Handheld Displays}

To the best of our knowledge, only a few studies concerning visual perception with small curved displays have previously been carried out. This fact may be partially due to previous low availability of hardware that has set limitations for research designs. Häkkinen et al. (2008) took an early attempt to clarify the effect of display curvature on reading by simulating the curved text with paper prints that were attached to curved pieces of plastic. By measuring subjective reading experience with various curvature magnitudes and directions, they found that low magnitudes were preferred over high magnitudes and that concave surfaces were preferred over convex surfaces. Furthermore, displays that were curved about the horizontal axis (i.e., perpendicular to the direction of text) were associated with better reading experience than displays that were curved about the vertical axis (i.e., to the direction of the text), which suggested that depth change adaptation was more difficult to implement along the sentences than between the lines of the text.

Wang et al. (2007) used laminated paper prints to investigate how the curvature $(r=$ $\pm 10 \mathrm{~cm}$ or planar) of electronic paper, when combined with different text-background colors, affects visual performance under two illuminations. By using a task in which the subjects searched for a target word on a page of text, they found no difference in accuracy between the curvatures. The subjects preferred to perform the task with the planar surface rather than with convex or concave prints, however. Similarly, Lin et al. (2008) used laminated prints to investigate the effects of curvature $(\mathrm{r}= \pm 10 \mathrm{~cm}$ or planar), illumination, and anti-reflective coating on visual performance and eye strain after reading. They measured performance by 
1 using the Pseudo-text search task, in which subjects search for and count the number of target

2 letters from strings of random letters that are arranged in rows, similar to normal text (Roufs

$3 \&$ Boschman, 1997). The results indicated that the presence of display coating (not the surface

4 curvature) modified search performance. Interestingly, the subjects reported less visual

5 fatigue after the pseudo-text search when curved prints were used rather than a planar surface.

6 The results of these two studies suggest that a certain amount of the surface curvature of

7 electronic paper can be tolerated without causing any notable effects on reading.

Pölönen et al. (2008) were the first researchers to report results that were obtained

9 with an actual flexible display. They presented short texts in a bended corner $(4 \mathrm{~cm} \times 5 \mathrm{~cm})$ of an OLED prototype and compared (in two illuminations) reading speed and the subjective

11 task load with two radius curvatures $(\mathrm{r}=-20 \mathrm{~cm}$ and $-10 \mathrm{~cm})$ to the reading speed and

12 subjective task load that were obtained when a planar surface was used. Despite the technical 13 constraints of the setup, the results implied that curving the display may increase the reading 14 speed for concave $(\mathrm{r}=-10 \mathrm{~cm})$ displays, when compared to planar displays. On the other hand, the same curvature was associated with the highest subjective task load after reading, 16 which suggested that reading from the curved surface demanded stronger commitment to the 17 task.

To summarize, previous research with curved surfaces suggests that viewing information from curved display devices may differ from viewing information from planar displays in regard to both subjective and objective measures, and the characteristics of surface

21 curvature seem to play an important role in visual performance. However, research on visual 22 performance with actual curved displays is missing.

\section{Present Study}

This study aimed to clarify how visual performance with small curved displays depends

24 on the direction and magnitude of the display curvature. We measured performance with a 


\section{VISUAL PERFORMANCE WITH CURVED DISPLAYS}

1 flexible display that was bent about its horizontal axis in order to form convex and concave

2 display surfaces with low $(\mathrm{r}=100 \mathrm{~mm})$ and high $(\mathrm{r}=50 \mathrm{~mm})$ radius curvatures. Due to the expected impact of display location on the optical characteristics and visual perception,

4 performance was measured based on the function of stimuli's distance from the display's

5 center point. Visual search was selected as the experimental method. Visual search has been

6 previously utilized for various research purposes in vision science (Palmer, Verghese, \&

7 Pavel, 2000; Wolfe \& Horowitz, 2004) and applied vision (e.g., Greene, Brown, \& Paradis, 8 2013; Ojanpää \& Näsänen, 2003). Because visual displays typically contain letters and other

9 alphanumeric information, we used letters as the stimuli of the search. In Experiment 1, we

10 validated the selected method by measuring how the contrast that is needed for target

11 detection changes along the retinal eccentricity on a planar display. In Experiment 2, this

12 effect was investigated with curved displays. In Experiment 3, we investigated more detailed processing of the displayed items on the concave and convex surfaces by measuring the time

14 that was required to search and identify displayed letters.

\section{General M ethod}

\section{A pparatus and Environment}

The display was a flexible 4.5-in. (800 x 480 pixels) AMOLED display. It was viewed in five configurations: Planar $(\mathrm{r}=0 \mathrm{~mm})$, low concave $(\mathrm{r}=-100 \mathrm{~mm})$, high concave $(\mathrm{r}=-50$

$17 \mathrm{~mm})$, low convex $(\mathrm{r}=100 \mathrm{~mm})$, and high convex $(\mathrm{r}=50 \mathrm{~mm})$ curvatures (Fig. 2$)$. The curvature was controlled by using five plastic molds that were specifically made for this purpose. The display was curved about its short side over the molds and attached to a stand in portrait orientation. Subjects viewed the display from a $45-\mathrm{cm}$ distance that was perpendicular

21 to the display center. The distance was controlled through use of a chin rest. 
The display was driven as the secondary display to a computer monitor via a Display

2 Module Controlling Unit (DMCU IV, Nokia) that converted the HDMI signal to the Video

3 Streaming Screen Interface (ViSSI, RGB I/F). Stimulus generation and presentation was

4 controlled by using MatLab with the Psychophysics Toolbox extension (Brainard, 1997) on a

5 PC that used the Windows operating system. Experiments were performed in a dim room. To

6 avoid reflections on the display, display surroundings were uniformly lit $\left(20 \mathrm{~cd} / \mathrm{m}^{2}\right)$ by two

7 vertical fluorescent lights that were front-covered with grey, non-reflective shields and

8 positioned on both sides of the display (Fig. 2). The immediate surroundings of the display

9 were covered with grey cardboard, and the background was covered with a grey, non-

10 reflective fabric.

\section{Display Characterization}

The display was characterized with a conoscope (Eldim VCMaster 3D Li,

13 measurement range $\pm 50^{\circ}$ ). The full white screen of the display in its planar state was 200

$14 \mathrm{~cd} / \mathrm{m}^{2}$ (as measured from the center point), with a contrast ratio (CR) of 15 000:1. The peak

15 brightness began to be reduced at $\pm 20^{\circ}$, and the brightness was only $64 \%$ of its original level

16 at $\pm 50^{\circ}$ (Table 1; Table 2). Because the black level that was measured for the CR was

17 essentially detector noise, the measured values fluctuated. The CR at the display center

18 indicates very high overall contrast performance, however. According to the chromaticity

19 coordinate system of the International Commission on Illumination (CIE 1976), the

20 coordinates for the display's white point were $u^{\prime}=0.187, v^{\prime}=0.461$ (Fig. 3). When the

21 display was curved, the white point drifted toward the green primary at eccentricities above

22 approximately $5^{\circ}$ (Table 1 ; Table 2$)$, and due to the high curvature magnitudes $(\mathrm{r}= \pm 50 \mathrm{~mm})$, 
1 the effect was quite prominent (Fig. 3). In the planar state, white point variation between the

2 eccentricities was minor $(< \pm .003)$ due to the small change in viewing angles $\left(< \pm 7^{\circ}\right)$.

Figure 3

\section{Experiment 1: Contrast-Based Target Detection with a Planar Display}

Luminance contrast is known to affect the processing speed when searching for letters (Boshman \& Roufs, 1997; Ojanpää \& Näsänen, 2003) and icons (Näsänen \& Ojanpää, 2003), as well as in target localization (Greene et al., 2013) and reading (Legge, Rubin, \& Luebker, 1987; Ojanpää \& Näsänen, 2003). Typically, performance sharply improves with increasing contrast at low contrast levels and then levels off at high contrast levels (Legge et al., 1987; Näsänen \& Ojanpää, 2003; Roufs \& Boschman, 1997). We assumed that a task that was based on the detection of small contrast differences would also be a sensitive measure of curvature-induced changes in visual performance. Therefore, we used a letter search task in which subjects were required to detect target letters that were surrounded by other letters based on the letter-background contrast.

The aim of Experiment 1 was to clarify two methodological aspects that were of importance for the experimentation with curved displays: Whether the search task was able to reveal any location-specific effects in visual processing, and whether the number of letters on the screen among which the target was to be detected would affect observers' performance. To consider the location-specificity of displayed objects, we measured performance based on the function of distance from the display's center point (i.e., eccentricity) with a planar display. This approach also takes into account the contrast sensitivity of the human eye, which decreases from the foveal vision to the periphery (Rovamo, Virsu, \& Näsänen, 1978). We assumed that with brief stimulus presentations (200ms), the display eccentricity would 
1 correspond to the retinal eccentricity, and thus, stimulus letters that appeared further away

2 from the display center would require higher target-distracter contrast for target detection. To consider the effect of the number of letters on the screen, we measured observers'

4 performance with different set sizes. Previous research has shown that visual search that is

5 based on simple features, such as orientation or color, is independent of set size (Palmer et al., 6 2000; Wolfe \& Horowitz, 2004), but using contrast as the guiding attribute of search is a less

7 studied characteristic (Wolfe \& Horowitz, 2004). When visual stimuli consist of high and low 8 contrast items, the high contrast items are typically easy to detect and hard to ignore.

9 However, when low contrast targets are presented among high contrast distractors, and the experimental design allows the observer to selectively attend the low contrast targets, contrast

11 resembles other simple features that guide the search (Pashler, Dobkins, \& Huang, 2004). We 12 reasoned that if the set size is irrelevant in regard to performance in the contrast-based letter detection task, only one set size is needed for experimentation with curved displays. eccentricities $\left(1.6^{\circ}-6.8^{\circ}\right)$, and with four set sizes $(2,4,8$, and 12$)$.

\section{M ethod}

Subjects. Three subjects (aged 33, 33, and 31 years) participated in the experiment. Two of them were authors of this paper (TM, JH), and one was naïve to the purpose of the experiment. All of the subjects reported normal vision and one of them wore glasses $(0 /-1.25$ diopters). The subjects were screened for normal near distance visual acuity (LEA Numbers Test@), normal contrast sensitivity (Functional Acuity Contrast Test; F.A.C.T.®), and normal

21 far distance visual acuity with high and low contrast stimuli (LEA Numbers Test ${ }^{\circledR}$ at $90 \%$ and $5 \%$ contrast). letters (O, S, N, Z, C, H, K, R, D, and V; Pelli, Robson, \& Wilkins, 1988). The same letter 
1 was used for all of the characters of each trial. The character height (pt 20) corresponded to

$20.42^{\circ}$. Letters were light grey on a mid-grey $\left(100 \mathrm{~cd} / \mathrm{m}^{2}\right)$ background. The contrast $\left[\mathrm{C}_{\text {Weber }}=\right.$

3 ( $\left.\mathrm{L}_{\text {Letters }}-\mathrm{L}_{\text {Background }}\right) / \mathrm{L}_{\text {Background] }}$ of the target letters varied from $18 \%$ to $78 \%$ (118 -178

$\left.4 \mathrm{~cd} / \mathrm{m}^{2}\right)$, with a step size of $12 \%$. The contrast of the distracter letters was $90 \%\left(190 \mathrm{~cd} / \mathrm{m}^{2}\right)$.

5 The stimuli were characterized on the plane through use of a spectroradiometer (PR-670

6 SpectraScan).

A trial begun with a light grey fixation cross $\left(0.31^{\circ}\right)$ that was shown in the center of the display for $500 \mathrm{~ms}$ (Fig. 4). After a $200 \mathrm{~ms}$ delay, a set of four to twelve stimulus letters appeared on the circumference of an imaginary circle at one of the five eccentricities $\left(1.6^{\circ}\right.$, $3.2^{\circ}, 4.8^{\circ}, 6.3^{\circ}$, or $6.8^{\circ}$;) for $200 \mathrm{~ms}$. The distance between two adjacent letters was always at

11 least half the eccentricity in order to avoid crowding (Bouma, 1970). Due to this requirement, 12 set size 8 was only included for $1.6^{\circ}-4.8^{\circ}$ eccentricities and set size 12 for $1.6^{\circ}-3.2^{\circ}$ eccentricities. The subjects' task was to decide whether one of the letters (target) had a different (letter-background) contrast than the others (distractors) in a two-alternative forced choice (2AFC) procedure. The target was present in $50 \%$ of the trials. Subjects responded by pressing one of two keys on the keyboard that were marked with green ("yes") and red ("no") colors. The accuracy of answers was emphasized. and target contrast varied from trial to trial in a random order. A stimulus block consisted of

21 half the trials that were needed for a set size and each block contained trials for one set size only. Presentation order for the blocks was counterbalanced between the subjects. Subjects were allowed to take short breaks between the blocks. Before the actual experiment, the subjects were trained on the task for ten minutes. During this period, the incorrect answers 


\section{VISUAL PERFORMANCE WITH CURVED DISPLAYS}

1 were signaled with a sound mark, which was not used in the actual experiment. The experiment was divided into several sessions, with each starting with a short training period.

Analysis of results. Search performance was measured as the sensitivity of target detection with the $d$-prime ( $d^{\prime}$ ) measure of Signal Detection Theory. D-prime is based on the proportions of the four response types (hit, miss, correct refusal, false alarm), and it is independent of response criteria (see Stanislaw \& Todorov, 1999). The values of $d$ ' were calculated by using the formula $d^{\prime}=\mathrm{z}(\mathrm{H})-\mathrm{z}(\mathrm{F})$, where $\mathrm{H}=$ hit rate, $\mathrm{F}=$ false alarm rate, and $\mathrm{z}()$ is a probit function. Trials with a response time over 10 seconds $(<0.2 \%)$ were excluded from the data. The mean response time was $740 \mathrm{~ms}(S D=381 \mathrm{~ms})$. (Linear Mixed Models, LMM) that treated Eccentricity $\left(1.6^{\circ}, 3.2^{\circ}, 4.8^{\circ}, 6.3^{\circ}, 6.8^{\circ}\right)$ and $S e t$ size $(2,4,8,12)$ as fixed factors and Subject as a random intercept. Post hoc comparisons were carried out by using the Bonferroni correction. The effect size of the full multilevel model was estimated with the reduction in mean square prediction error according to Snijders' and Bosker's (1999) formula:

$$
\begin{gathered}
R_{1}^{2}=1-\frac{\operatorname{var}\left(Y_{i j}-\sum_{h} \gamma_{h} X_{h i j}\right)}{\operatorname{var}\left(Y_{i j}\right)} \\
=1-\frac{\hat{\sigma}^{2}(\text { full })+\tau_{0}^{2}(\text { full })}{\hat{\sigma}^{2}(\text { null })+\hat{\tau}_{0}^{2}(\text { null })},
\end{gathered}
$$

where $Y_{i j}$ is the outcome variable, $\gamma_{h}$ is the coefficient for outcome variable $X_{h i j}$ for all $h$

variance at the second level.

\section{Results and Discussion}


VISUAL PERFORMANCE WITH CURVED DISPLAYS

1 decreased when the distance from the center increased from $1.6^{\circ}\left(d^{\prime}=2.66\right)$ to $3.2^{\circ}\left(d^{\prime}=\right.$

$22.31, p=.018)$, from $3.2^{\circ}$ to $4.8^{\circ}\left(d^{\prime}=1.82, p<.001\right)$, and from $6.3^{\circ}\left(d^{\prime}=1.62\right)$ to $6.8^{\circ}\left(d^{\prime}=\right.$

$31.07, p=.007)$. Set size did not affect the performance $[\mathrm{F}(3,28)=1.84, p=.164]$. No

4 Eccentricity $x$ Set size interaction was obtained $[\mathrm{F}(7,28)=1.33, p=.276]$. The observed effect

$5 \quad$ size of the full model was $R^{2}=.77$.

Figure 5

The fact that the contrast required for target detection strongly depended on target eccentricity demonstrates that the task was sensitive to the location-specific effects of search. This suggests that the contrast-based letter detection task could also be used in measuring

10 curvature-induced performance changes at different display locations. Furthermore, because 11 the results indicated that performance did not depend on the set size, only one set size needs to be used in the next phase of the study.

\section{Experiment 2: Contrast-Based Target Detection with Curved Displays}

The aim of Experiment 2 was to investigate whether the detection of displayed items

21 the planar display at five eccentricities $\left(1.6^{\circ}-6.8^{\circ}\right)$. 
VISUAL PERFORMANCE WITH CURVED DISPLAYS

M ethod

Subjects. The same three subjects participated as in Experiment 1.

Stimuli and procedure. The stimuli and procedure were similar to Experiment 1 (Fig.

3 4), with the exception that only one set size was used (set size 4). The five display

4 configurations (planar, low concave, high concave, low convex, high convex) were tested in

5 separate blocks. The local effects of curving at different eccentricities are shown in Table 1. A

6 stimulus block consisted of half the trials that were needed for a curvature. Presentation order

7 for the blocks was counterbalanced between the subjects.

Analysis of results. Search performance was measured as the sensitivity of target detection ( $d$ '). Additionally, the subjects' individual performance was examined based on the

11 accuracy data. Psychometric functions were fit to these data by using a Bootsrapping 12 procedure with 1000 replications (Foster \& Bischof, 1997). Trials with a response time over

1310 seconds $(<0.3 \%$ of the data) were excluded from the analysis of results. The mean 14 response time was $747 \mathrm{~ms}(\mathrm{sd}=396 \mathrm{~ms})$. Statistical significance of d-prime values was tested by using a random intercept model

16 (Linear Mixed Models, LMM) that treated Eccentricity $\left(1.6^{\circ}, 3.2^{\circ}, 4.8^{\circ}, 6.3^{\circ}, 6.8^{\circ}\right)$ and

17 Curvature (high concave, low concave, planar, low convex, high convex) as fixed factors and 18 Subject as a random intercept. Post hoc comparisons were carried out by using the Bonferroni 19 correction. 


\section{Results and Discussion}

The sensitivity of target detection $\left(d^{\prime}\right)$ with five display configurations is illustrated in

2 Figure 6. Contrary to our hypothesis, Curvature had no significant effect on performance

$3[\operatorname{LMM} F(4,48)=1.93, p=.121]$, which was demonstrated by the overlapping d-prime values

4 in the figure. As expected, sensitivity declined with increasing Eccentricity $[F(4,48)=98.62$,

$5 \quad p<.0001$; Fig. 6]; there was a significant difference in sensitivity between $3.2^{\circ}$ and $4.8^{\circ}(p<$

$6.0001)$ and between $6.3^{\circ}$ and $6.8^{\circ}(p<.0001)$. No Curvature x Eccentricity interaction was

7 obtained $[F(16,48)=.72, p=.760]$. The observed effect size of the full model was $R^{2}=.77$.

To reveal individual differences in response to curved display surfaces, we observed changes in each subject's performance accuracy. Similar to the d-prime values, the

11 psychometric functions that were drawn from these data demonstrated a rather small effect of curvature on target detection (Fig. 7). At 1.6-6.3 eccentricities, the performances follow a similar pattern of being dependent on eccentricity but only demonstrating small and inconsistent differences between the curvature variants. At $6.8^{\circ}$, the deviation between single observations increases, but there was still no consistent pattern that favored any of the curvatures. It appears instead that the deviation is due to the difficulty of the task at the given eccentricity, which could result from the reduced contrast sensitivity of the eye. The increased difficulty of target detection with high eccentricity stimuli was also highlighted in the subjects' comments. In fact, based on the comments, experienced difficulty of the task was also increased by the high magnitude curvature of the display. This notion is consistent with

21 previous work, which suggested that the increased demands of a visual task might be seen in 
1 the subjective evaluations before they are seen in the objective performance measures

2 (Boschman \& Roufs, 1997; Pölönen et al., 2008; Wang et al., 2007).

It should be noted here that the actual eccentricities for the curved displays were somewhat smaller than the standard values that were defined with the planar display (Table 1). Due to the foreshortening of curved display area, the actual values differed from the standard by $.001^{\circ}$ to $1.53^{\circ}(M=.35 ; S D=.44)$. The true variation in stimulus eccentricities was smaller, however, because no letters greater than $3.2^{\circ}$ appeared at the midline of the display from which the minimum eccentricities were defined. Still, this between-curvatures difference was largest for stimuli that were presented at $6.8^{\circ}$, which may have added variation to the performance data at this distance that was close to the display edges. defined by the targets' location relative to the display center rather than by the curvature of

14 the display. The targets were detected similarly across the curvatures despite their large variation in letter slants (up to $53^{\circ}$; Table 1) and the foreshortening of retinal image (up to $49 \%$ of target height). Previous research has shown that perspective distortions are effectively corrected by the visual system. For instance, processing times for rotated words have been shown to remain at a constant level for up to $\pm 60^{\circ}$ vertical and horizontal rotation (Grossman et al., 2007; Larson et al., 2000). Consistent with these findings, our results demonstrated that displayed targets were detected similarly independent of the local curvature, which indicates

21 that efficient compensation of retinal distortions was produced by the curved display surface.

22 This suggests that under optimal viewing conditions, simple target detection from a small

$23\left(4.5^{\prime \prime}\right)$ curved display can maintain the level that is reached with the planar display, even when 24 the display is bent to $\pm 50 \mathrm{~mm}$ radius curvature. 
A plausible reason for the small effect of curvature on performance is provided by the

2 high native CR of the display. Despite the large variation in viewing angles between the

3 curvature variants and in brightness reduction towards the display edges (Table 1), the

$4 \quad 15$ 000:1 CR was able to reproduce the greyscale at a sufficiently steady level across the

5 curvatures. Because the perceived contrast for a particular display location did not differ

6 between the curvature variants, performance in the contrast-based target detection was

7 defined by the retinal eccentricity alone. Consequently, performance with the curved displays closely resembled the performance that was obtained with the planar display. Because the task was based on the perception of the luminance contrast, variation in the display's white point did not even alter performance (Table 1; Figure 3).

However, the contrast-based detection task that was employed in Experiment 2 did not require detailed processing of displayed information. Instead, it appears that with a large enough contrast difference, the target stood out among the otherwise identical distractors, which is similar to findings that are typically reported after using a single feature search (Palmer et al., 2000; Pashler et al., 2004; Wolfe \& Horowitz, 2004). Although curving the display did not affect simple target detection, it might still affect performance in visual tasks that require a more elaborate analysis of the displayed information (Wolfe \& Horowitz, 2004). Furthermore, because the lowered contrast sensitivity of the eye generally made visual processing difficult at high eccentricities, it is possible that certain between-curvature effects were covered. Performance differences outside the central display are of special importance in regard to curved displays because the local changes are largest when they are close to the display edges. These effects were further investigated in Experiment 3.

\section{Experiment 3: Threshold Letter Search Time with Curved Displays}


1 displayed items. Second, we wished to clarify the curvature effect for areas outside the central

2 display. For these purposes, we employed another visual search task in which subjects

3 searched for a target letter that was surrounded by other letters based on letter identity and

4 measured the time that was required for a successful search (i.e., threshold search time).

5 Because letter identity is not a preattentive feature that would facilitate target detection

6 (Wolfe \& Horowitz, 2004), the subject must serially fixate on and identify each letter on the

7 screen in order to find the target. The time that is required for this process greatly depends on

8 the difficulty of the task (e.g., number of distracters) and on the viewing conditions (e.g.,

9 display curvature), which modify the fixation durations and the number of fixations that are

10 needed for the search (Rayner, 2009). Furthermore, target processing in peripheral vision as

11 opposed to central vision requires more eye movements and more time (Scialfa \& Joffe, 12 1998).

Threshold search times for the five curvatures were defined at four eccentricities from

14 the display center $\left(1.6^{\circ}, 5.3^{\circ}, 5.9^{\circ}\right.$, and $\left.6.6^{\circ}\right)$. The term eccentricity is used here for

15 consistency, even though this measure does not necessarily correspond to retinal eccentricity

16 in the present setup. The difficulty of the task was varied by changes in set size (8 or 12). We

17 hypothesized that thresholds would be higher with high curvature magnitudes and with

18 convex rather than concave displays. It was also hypothesized that threshold differences

19 between the curvatures would increase as the eccentricity and set size increased.

\section{M ethod}

Subjects. Subjects were eight students and staff of Aalto University (age range: 23-33

21 years, mean: 27.4 years). One of them was an author of this study (TM), and the others were

22 naïve to the purpose of the experiment. All of the subjects reported normal or corrected-to-

23 normal vision and wore their typical eye-correction equipment during the experiment. They

24 were screened for normal visual acuity and contrast sensitivity, similar to Experiments 1 and 


\section{VISUAL PERFORMANCE WITH CURVED DISPLAYS}

1 2. Subjects received two movie tickets or lunch vouchers as compensation for their

2 participation.

Stimuli and procedure. Stimulus letters were again drawn from the set of ten Sloan

4 letters. One of the letters was the target ( $\mathrm{H}$ or $\mathrm{R})$, which remained the same during the whole

5 experiment. The target was present in $50 \%$ of the trials, and it appeared at each letter position

6 with an equal probability. The distractor letters were randomly selected for each trial from the

7 set of nine remaining characters, with the restriction being that a maximum of two of the same

8 letters was present in a trial. As characterized on the planar display, the letter height (14 pt)

9 corresponded to a $0.28^{\circ}$ of visual angle. All of the letters were light grey $\left(160 \mathrm{~cd} / \mathrm{m}^{2}\right)$ and

10 were on a mid-grey $\left(100 \mathrm{~cd} / \mathrm{m}^{2}\right)$ background $\left(\mathrm{C}_{\text {Weber }}=60 \%\right)$. Two set sizes were employed $(8$,

11 12). All of the letters for a trial were presented equidistant from the fixation cross at one of

12 the four eccentricities $\left(1.6^{\circ}, 5.3^{\circ}, 5.9^{\circ}\right.$, and $6.6^{\circ}$; Table 2$)$. Letter-to-letter distance was always 13 at least $0.78^{\circ}$. At $6.6^{\circ}$ eccentricity, only a set size of 8 was used.

A trial began with a fixation cross $\left(0.31^{\circ}\right)$ being presented in the center of the display for $500 \mathrm{~ms}$ (Fig. 8). After a $200 \mathrm{~ms}$ delay, the stimulus letters were briefly presented on the

17 display. The subjects' task was to decide whether the target was present or not (2AFC). They

18 responded by pressing one of the two keys on the keyboard that were marked with green

19 ("yes") and red ("no") colors. 
The duration of the stimulus presentation was varied through the use of an adaptive

2 staircase algorithm (Wetherill \& Levitt, 1965; cf. Näsänen \& Ojanpää, 2003; Ojanpää \&

3 Näsänen, 2003). In the beginning of each block, the presentation duration was 1000 ms. After

4 an incorrect response, the duration of the next stimulus presentation was increased by a factor

5 1.26. Conversely, after three consecutive correct responses, the duration of the next stimulus

6 presentation was decreased by the same factor. This staircase procedure was continued until

7 the eighth reversal on the staircase. A threshold estimate that indicated a 79\% probability of

8 the subject choosing a correct answer was defined as the average of these reversals. The first

95 trials were not taken into account in this threshold estimate.

The experiment consisted of ten blocks, each of which contained trials for only one set

11 size and curvature. Within a block the trials for each eccentricity were presented

12 consecutively in a random order. The order of the blocks was counterbalanced between the subjects. Subjects practiced the task for 10 minutes before starting the actual experiment.

Analysis of results. Threshold search times were defined for five display curvatures, at four eccentricities, and with two set sizes. The average number of trials that was needed for a threshold estimate was $44(S D=12)$ and $41(S D=11)$ for set sizes 8 and 12 , respectively.

Statistical significance of the estimates was tested through use of the LMM by treating hoc comparisons were carried out by using the Bonferroni correction.

\section{Results and Discussion}

Threshold search times are plotted in Figure 9. Consistent with our hypotheses, the 


\section{VISUAL PERFORMANCE WITH CURVED DISPLAYS}

1 curvatures $(\mathrm{r}= \pm 50 \mathrm{~mm})$ than the low curvatures $(\mathrm{r}= \pm 100 \mathrm{~mm} ; p<.01)$, whereas

2 performance with the low curvatures and the planar display did not differ $(p>.05)$. The

3 prolonged search times were consistent with the subjects' comments regarding the difficulty

4 of the task. Thresholds were also higher for targets that were presented at intermediate

5 eccentricities $\left(5.3-5.9^{\circ}\right)$ than for targets that were near the display center $\left(1.6^{\circ} ; p<.001\right)$, and

6 the highest thresholds were obtained near the display edges $\left(6.6^{\circ} ; p=.002\right)$. As expected, set

7 size 12 resulted in longer threshold search times than set size 8.

A significant Curvature $x$ Eccentricity interaction was also found $[F(12,238)=2.21, p$ $=.012$; Fig. 10]. Close to the display center $\left(1.6^{\circ}\right)$, threshold durations for convex displays were slightly shorter than thresholds for planar and concave displays. As the distance from the display center increased, performance with all of the curved displays decreased in relation to performance with the planar display, however. With convex displays, this performance drop 14 peaked at approximately $6^{\circ}$, which indicated that the convex displays had $100 \mathrm{~ms}$ (for low convex) to $230 \mathrm{~ms}$ (for high convex) higher thresholds than the planar display at that distance. With concave displays, the relative change was smoother, with there being a $70 \mathrm{~ms}$ (for low concave) to $130 \mathrm{~ms}$ (for high concave) relative increase at peak thresholds of approximately $5^{\circ}$. These findings indicate that performance with convex displays and with a high convex curvature, in particular, was more dependent on the display location than performance with the concave counterparts was. In fact, average thresholds with the high convex curvature varied from $320 \mathrm{~ms}$ to $730 \mathrm{~ms}$ (> $400 \mathrm{~ms}$ ), depending on eccentricity, whereas the variance with the low convex curvature (300 ms) and both concave curvatures (250 ms) was smaller. 
Moreover, Figure 10 suggests that performance with the curved displays improved relative to performance with the planar display for eccentricities beyond the $5-6^{\circ}$. This change was due to a performance drop in the planar display rather than to actual improvement in the curved displays because search speed with the planar display also slowed down beyond $6^{\circ}$ (Fig. 9). It appears that the demands of the task were generally increased at areas that were close to the display edges, which resulted in prolonged threshold durations with all of the display variants.

Whereas Experiment 2 indicated no difference in target detection between the curvature variants, Experiment 3 demonstrated that search speed for the displayed targets was clearly reduced with high curvature magnitudes. This reflects the different requirements of the

11 visual tasks that were employed in the experiments. Interestingly, the constant performance across the curvatures in the contrast-based target detection (Experiment 2) suggests that prolonged threshold letter search times that were associated with the high curvature magnitudes (Experiment 3) were not due to changes in contrast. The reduced performance must, therefore, result from other optical characteristics and local changes in stimulus features (Table 2).

Both brightness and the white point underwent a notable change when the display was bent to high radius curvatures. Although the perceived contrast of the display was not affected, these changes likely interacted with other local changes in the displayed stimuli. The letters on the high curvatures were slanted over $50^{\circ}$ at their highest slant. Although this high amount of perspective change can be corrected by the vision system without there being a notable effect on the observer's performance (Grossman et al., 2007; Larson et al., 2000;

23 Rosinski et al., 1980; Vishwanath et al., 2005), the resulting foreshortening in stimulus size may have slowed down the speed of search in the present case. The size reduction from the central display $\left(1.6^{\circ}\right)$ to near the display edges $\left(6.6^{\circ}\right)$ was approximately $28 \%$ with high concave curvatures and $46 \%$ with high convex curvatures. The corresponding values for the 
1 low concave and convex curvatures (both with up to $25^{\circ}$ letter slants) were $4 \%$ and $16 \%$,

2 respectively (Table 2). The larger variation in character height would also explain why

3 performance with convex curvatures depended more on eccentricity than performance with

4 the concave curvatures did.

Furthermore, the depth change that was associated with curved surfaces may have

6 affected performance for the high convex and concave displays. Although the stimuli were

7 always presented with one eccentricity at a time, the depth change between characters that were simultaneously shown on the display was largest with the high curvature magnitudes.

The depth change, in turn, may have triggered accommodation and vergence responses of the eye that take time to develop and stabilize (Campbell \& Westheimer, 1960; Fincham \&

11 Walton, 1957; Rashbass \& Westheimer, 1961). The effect of such adaptive responses is

12 evident on tasks that measure the speed of processing visual details.

\section{General Discussion}

The effect of display curvature on visual performance depended on the type of visual

14 task. In the contrast-based target detection task (Experiments 1 and 2), the direction and 15 magnitude of curvature did not affect performance (when compared to the planar display). In the search task that required more elaborate processing of displayed items in order to identify the targets (Experiment 3), performance was clearly reduced with high radius curvatures $(\mathrm{r}=$

$18 \pm 50 \mathrm{~mm}$ ), especially in regard to the convex form. In both tasks, performance strongly

19 depended on the distance from the display center at which the displayed items appeared. In 20 particular, performance beyond $6^{\circ}$ eccentricity severely declined.

\section{Target Detection and Speed of Search with Curved Displays}

In Experiment 2, the displayed targets were detected similarly across the curvatures.

22 The sensitivity and accuracy of contrast-based target detection were determined by the 
1 eccentricity of the displayed items rather than by the direction or magnitude of the curvature.

2 The eccentricity effect was an expected finding because the contrast sensitivity of the eye is

3 known to decrease with retinal eccentricity (Rovamo et al., 1978; Cannon, 1985). However,

4 the fact that the effect was of a similar magnitude to the planar display as to all of the

5 curvatures suggests that curving the display had no influence on the retinal contrast reduction.

6 The results can be interpreted in light of interplay between the display's optical characteristics

7 and the nature of the task. The high native contrast and wide viewing angles of the display

8 enabled detection of small contrast differences, even when the display was bent to a small

9 curvature radius. Because the contrast was similarly perceived across the curvatures,

performance in the contrast-based detection task only depended on the eccentricity of stimuli.

11 This indicates that contrast acted as the single guiding feature of search in the task (cf.,

12 Pashler et al., 2004; Wolfe \& Horowitz, 2004). In contrast, local changes in other optical characteristics (e.g., brightness, white point) or stimulus features (e.g., character height) that occurred when the display was curved did not play a role in the subjects' performance on the task. One should keep in mind, however, that the visual tasks that were employed here only required processing of greyscale (not color coded) information. Still, because contrast is a key determinant of legibility with visual display units (Boschman \& Roufs, 1997; Ojanpää \& Näsänen, 2003), the result suggests that curving a display does not easily disrupt the detection of displayed items under optimal viewing conditions.

However, the prolonged processing times that were associated with the high curvature magnitudes $(\mathrm{r}= \pm 50 \mathrm{~mm})$ in Experiment 3 indicated that processing visual details becomes more laborious with curved displays. The processing times were further increased by adding to the number of to-be-processed items that was on the display. Because the perceived contrast of the stimuli did not differ between the curvatures (Experiment 2), the increased demands most likely did not result from poor legibility of the letters. Instead, the prolonged threshold durations could reflect the amount of local changes in visual stimuli with which 
1 observers must cope while performing the task. For instance, at $6.6^{\circ}$ eccentricity, the high

2 curvature magnitudes resulted in an average change of $53^{\circ}$ for the viewing angle and in an

3 average $37 \%$ reduction in letter height. The corresponding values with low curvature

4 magnitudes $(\mathrm{r}= \pm 100 \mathrm{~mm})$ were $23^{\circ}$ for the viewing angle and $9 \%$ for the letter height.

Because the thresholds for the low radius curvatures did not differ from the planar

6 display, it appears that a notable amount of changes were tolerated by the visual system

7 before the processing speed of the displayed items was slowed down. This finding is consistent with previous research related to visual performance with curved surfaces. Wang et al. (2007) and Lin et al. (2008) found that $\pm 100 \mathrm{~mm}$ radius curvature had no influence on visual performance with simulated electronic paper. Similarly, results by Grossman et al.

11 (2007) and Larson et al. (2000) demonstrated that rotations of displayed text have negligible

12 effects up to a $\pm 55-60^{\circ}$ change (after this, performance declines sharply). When combined with the present results, these findings suggest that low curvature ratios do not alter visual performance with small displays in optimal viewing conditions. However, curvature magnitudes at a radius size of approximately $50 \mathrm{~mm}$ already cause a noticeable decrease in the speed of visual processing. Such decrements are particularly evident with convex display 17 surfaces.

\section{Limitations and Future Directions}

Certain aspects must be considered in regard to the generalization of the present results.

First, because the study aimed to investigate baseline visual performance with curved displays without there being intervening environmental factors, the experiments were conducted in dim indoor lighting. The applicability of the results for other lighting conditions is, therefore, limited. This is particularly true in regard to bright outdoor lighting because the current

23 flexible technologies still encounter problems regarding sunlight readability. With emissive

24 OLED displays, performance is limited due to the metal electrodes in the display structure. 
1 These electrodes have high reflectance, which reduces the display contrast under strong

2 external light (Singh et al., 2012; Yang et al., 2005). Reflective technologies that are used in

3 electronic paper utilize ambient light as the light source rather than a display backlight, and

4 performance with such displays should, therefore, improve with an increasing intensity of

5 light. There are always surface reflections on electronic paper, however, and excess

6 illumination can cause additional side effects, such as glares, that further impair the ambient

7 contrast (e.g., He, Torrance, Sillion, \& Greenberg, 1991; Lin et al., 2008).

The illumination effects are further complicated by the curved display surface.

9 Generally, the main advantage of concave displays is the reduced number of surface reflections on the display that curves toward the viewer's eyes (Fig. 1). This benefit, which

11 enhances optical characteristics, is lost or even reversed with convex displays because the

12 light scatters away from the outward-curved surface. The lowering of visual performance that 13 is associated with convex displays is, therefore, likely to be intensified by high illumination levels. Despite the higher vulnerability in ambient light, convex displays are still important in display design because convex surfaces are well suited in certain display applications, such as wearable electronics (Co, \& Pashenkov, 2008; Vertegaal \& Poupyrev, 2008). Further investigation is needed in order to reveal how the characteristics of ambient light would modify performance on different types of visual tasks that are performed with curved displays.

Second, future research should clarify how visual processing with curved displays is

21 influenced by the displayed contents. The visual stimuli in the present study consisted of

22 single legible letters that were presented at a noticeable distance from each other. Still, 23 increasing the set size of the displayed items from 8 to 12 significantly decreased the 24 observers' performance on the identification task. This suggests that with high-density 25 information, the degradation would be more severe. Furthermore, the spatial frequency content of the displayed information affects the accommodation response of the eye (Okada et 
1 al., 2006). With high-frequency content, changes in retinal blur are easily detected, which

2 triggers corrective actions by the vergence-accommodation system. With low-frequency

3 content, the blur is more difficult to detect, and corrective actions do not occur. Because the

4 accommodative corrections take time to develop (Campbell \& Westheimer, 1960; Fincham \&

5 Walton, 1957), the frequency content can greatly modify the processing speed of information

6 with curved displays in which the depth change between display locations generates retinal

7 blur. In addition to resulting from the high density of displayed information, the effect can

8 result from the high spatial resolution of the display.

\section{Conclusions and Implications}

When compared to conventional planar displays, even the static non-planar displays allow for a greater degree of freedom in device design (Vertegaal \& Poypyrev, 2008). Curved display surfaces enable display integration on everyday objects and wearable electronics, and eventually, complete devices will be deformable. Moreover, deformable materials enable novel interaction techniques that are based on the physical deformation of the display. A large amount of research in recent years has reported concepts in which the user communicates through use of the shape itself by bending, curving, or folding the display (e.g., Herkenrath et al., 2008; Khalilbeigi et al., 2012; Kildal et al., 2012; Lahey et al., 2011; Lee et al., 2010; Pillias et al., 2013; Roudaut et al., 2013; Schwesig et al., 2004). Therefore, deformable display materials are likely to have a great effect on the future of human-computer interaction. As device concepts approach real products and technology matures, understanding the advantages and limitations of such concepts from the perspective of human perception and

21 performance becomes increasingly important. The present study provides a baseline for visual performance with deformable displays by demonstrating how the direction and magnitude of static curvature affect visual search with small displays under optimal viewing conditions. By

24 showing that observers' performance was independent of curvature in simple detection tasks 


\section{VISUAL PERFORMANCE WITH CURVED DISPLAYS}

1 and with low radius curvatures $(\mathrm{r}= \pm 100 \mathrm{~mm})$, we demonstrate that the visual system

2 compensates for a large degree of the changes that are caused by curving in high-quality

3 displays. With high curvature magnitudes $(\mathrm{r}= \pm 50 \mathrm{~mm})$, the identification of displayed items

4 clearly decreased in speed, however. This was particularly true of the convex curvature, with

5 which the speed of processing strongly depended on the display location. Because the

6 curvature effects are supposed to be intensified by high intensity light, using such high

7 magnitude curvatures in portable devices should be avoided. Furthermore, critical information

8 should not be presented near the display edges because both sensitivity and the speed of

9 search were reduced in locations that were beyond $5-6^{\circ}$ from the display center. Finally, the

10 future design of display applications should consider that visual performance with curved

11 displays depends on the characteristics of the display and environment, as well as the current

12 visual task. Visual performance and ergonomics with curved display surfaces should remain 13 an active focus of research as long as visual processing is the primary information channel in 14 display applications.

Key points

- Viewing a curved display differs from viewing a planar display due to changes in display optics and geometry, viewing angle, and accommodative responses of the eye. These changes can affect visual perception and performance.

- Here we compared visual performance with a flexible display in a planar and four curved configurations. The curved displays differed with respect to the direction (i.e., concave, convex) and magnitude (i.e., low, high) of curvature.

- The direction or magnitude of curvature did not change users' sensitivity for target detection in a simple target detection task. However, the speed of target identification 
VISUAL PERFORMANCE WITH CURVED DISPLAYS

slowed down significantly when the task was presented on a display with high curvature magnitude, particularly for the convex form.

- The findings suggest that high magnitude curvatures cause large local changes in visual stimuli that decrease the speed of visual processing. Such decrements are particularly critical for portable devices because the ambient light of changing environments further challenges the legibility of the displayed details. Therefore, high curvature magnitudes should be avoided.
References
Boschman, M. C., \& Roufs, J. A. J (1997). Text quality metrics for visual display units: II. An experimental survey, Displays, 18, 45-64. doi: 10.1016/S0141-9382(97)00004-8

Bouma, H. (1970). Interaction effects in parafoveal letter recognition. Nature, 226, 177-178.

Brainard, D. H. (1997). The Psychophysics Toolbox, Spatial Vision, 10, 433-436.

Campbell, F. W. (1957). The depth of field of the human eye. Optica Acta: International Journal of Optics, 4(4), 157-164. doi: 10.1080/713826091

Campbell, F. W., \& Westheimer, G. (1960). Dynamics of accommodation responses of the human eye. The Journal of Physiology, 151, 285-295.

Cannon, M. W., Jr. (1985). Perceived contrast in the fovea and periphery. Journal of the Optical Society of America, 2(10), 1760-1768. doi: 10.1364/JOSAA.2.001760

Chen, Y., Au, J., Kazlas, P., Ritenour, A., Gates, H., McCreary, M. (2003, May 8). Flexible active-matrix electronic ink display. Nature, 423, 136. doi: 10.1038/423136a

Co, E., \& Pashenkov, N. (2008). Emerging display technologies for organic user interfaces. Communications of the ACM, 51(6), 45-47.doi: 10.1145/1349026.1349036 
1 Fincham, E. F., \& Walton, J. (1957). The reciprocal actions of accommodation and convergence. The Journal of Physiology, 137, 488-508.

Foster, D. H., \& Bischof, W. F. (1997). Bootstrap estimates of the statistical accuracy of thresholds obtained from psychometric functions. Spatial Vision, 11(1), 135-139.

Gambra, E., Sawides, L., Dorronsoro, C., \& Marcos, S. (2009). Accommodative lag and fluctuations when optical aberrations are manipulated. Journal of Vision, 9(6), 1-15.

Greene, H. H., Brown, J. M., \& Paradis, B. A. (2013). Luminance contrast and the visual span during visual target localization. Displays, 34, 27-32. doi: 10.1016/j.displa.2012.11.005

Grossman, T., Wigdor, D., \& Balakrishnan, R. (2007). Exploring and reducing the effects of orientation on text readability in volumetric displays. In M. B. Rosson, \& D. J. Gilmore (Eds.), CHI 'O7 Proceedings of the SIGCHI Conference on Human Factors in

He, X. D., Torrance, K. E., Sillion, F. X., \& Greenberg, D. P. (1991). A comprehensive physical model for light reflection. ACM SIGGRAPH Computer Graphics, 25(4), 175186. doi: $10.1145 / 127719.122738$

Herkenrath, G., Karrer, T., \& Borchers, J. (2008). TWEND: Twisting and bending as new

Häkkinen, J., Pölönen, M., Salmimaa, M., \& Hautanen, J. (2008). Reading experience with curved hand-held displays. Journal of the Society for Information Display, 16(11), 1099-1103. doi: 10.1889/JSID16.11.1099 
VISUAL PERFORMANCE WITH CURVED DISPLAYS

1 Kalyani, N. T., \& Dhoble, S. J. (2012). Organic light emitting diodes: Energy saving lighting technology_A review. Renewable and Sustainable Energy Reviews, 16, 2696-2723. doi: 10.1016/j.rser.2012.02.021

Khalilbeigi, M., Lissermann, R., Kleine, W., \& Steimle, J. (2012). FoldMe: Interacting with double-sided foldable displays. In R. Vertegaal, S. N. Spencer, Y. Fernaeus, A. Girouard, \& S. Jordà (Eds.), TEI '12 Proceedings of the Sixth International Conference on Tangible, Embedded and Embodied Interaction (pp. 33-40). New York: ACM. doi: $10.1145 / 2148131.2148142$

Kildal, J., Paasovaara, S., \& Aaltonen, V. (2012). Kinetic device: Designing interactions with a deformable mobile interface. In J. A. Konstan, E. H. Chi, \& K. Höök (Eds.), CHI '12 Extended Abstracts on Human Factors in Computing Systems (pp.1871-1876). New York: ACM. doi: 10.1145/2212776.2223721

Lahey, B., Girouard, A., Burleson, W., \& Vertegaal, R. (2011). PaperPhone: Understanding the use of bend gestures in mobile devices with flexible electronic paper displays. In D. S. Tan, S. Amershi, B. Begole, W. A. Kellogg, \& M. Tungare (Eds), CHI'11 Proceedings of the SIGCHI Conference on Human Factors in Computing Systems (pp. 1303-1312). New York: ACM. doi: 10.1145/1978942.1979136

Larson, K., van Dantzich, M., Czerwinski, M., \& Robertson, G. (2000). Text in 3D: Some legibility results. In T. Turner, G. Szwillus, M. Czerwinski, F. Peterno, \& S. Pemberton (Eds.), CHI 'OO Extended Abstracts on Human Factors in Computing Systems (pp. 145146). New York: ACM. doi: 10.1145/633292.633374

Lee, D.-S., Shieh, K.-K., Jeng, S.-C., \& Shen, I.-H. (2008). Effect of character size and lighting on legibility of electronic papers. Displays, 29, 10-17. doi:10.1016/j.displa.2007.06.007 
VISUAL PERFORMANCE WITH CURVED DISPLAYS

1 Lee, S.-S., Kim, S., Jin, B., Choi, E., Kim., B., Jia, X., Kim, D., \& Lee, K. (2010). How users manipulate deformable displays as input devices. In E.D. Mynatt, D. Schoner, G. Fitzpatrick, S. E. Hudson, W. K. Edwards, \&T. Rodden (Eds.), CHI'10 Proceedings of the SIGCHI Conference on Human Factors in Computing Systems (pp. 1647-1656). New York: ACM. doi: 10.1145/1753326.1753572

Legge, G. E., Rubin, G. S., \& \& Luebker, A. (1987). Psychophysics of reading. V. The role of contrast in normal vision. Vision Research, 27, 1165-1177. doi: 10.1016/00426989(87)90028-9

Lin, Y.-T., Lin, P.-H., Hwang, S.-L., Jeng, S.-C., \& Lin, Y.-R. (2008). Ergonomic evaluation of electronic paper: Influences of anti-reflection surface treatment, illumination, and curvature on legibility and visual fatigue. Journal of the Society for Information Display, 16(1), 91-99. doi: 10.1889/1.2835042

Maxwell, J., Tong, J., \& Schor, C. M. (2012). Short-term adaptation of accommodation, accommodative vergence and disparity vergence facility. Vision Research, 62, 93-101. doi: $10.1016 /$ j.visres.2012.03.013

Maxwell, J., Tong, J., \& Schor, C. M. (2010). The first and second order dynamics of accommodative convergence and disparity convergence. Vision Research, 50, 17281739. doi: 10.1016/j.visres.2010.05.029

Norman, J. F., Todd, J. T., Norman, H. F., Clayton, A. M., \& McBride, T. R. (2006). Visual discrimination of local surface structure: Slant, tilt, and curvedness. Vision Research, 46, 1057-1069. doi: 10.1016/j.visres.2005.09.034

Näsänen, R., \& Ojanpää, H. (2003). Effect of image contrast and sharpness on visual search for computer icons. Displays, 24, 137-144. doi: 10.1016/j.displa.2003.09.003 
VISUAL PERFORMANCE WITH CURVED DISPLAYS

1 Ojanpää, H., \& Näsänen, R. (2003). Effects of luminance and colour contrast on the search of information on display devices. Displays, 24, 167-178. doi: 10.1016/j.displa.2004.01.003

Okada, Y., Ukai, K., Wolffson, J. S., Gilmartin, B., Iijimati, A., \& Bando, T. (2006). Target spatial frequency determines the response to conflicting defocus- and convergencedriven accommodative stimuli. Vision Research, 46(4), 475-484. doi:10.1016/j.visres.2005.07.014

Palmer, J., Verghese, P., \& Pavel, M. (2000). The psychophysics of visual search. Vision Research, 40, 1227-1268. doi: 10.1016/S0042-6989(99)00244-8

Pashler, H., Dobkins, K., \& Huang, L. (2004). Is contrast just another feature for visual selective attention? Vision Research, 44, 1403-1410. doi: 10.1016/j.visres.2003.11.025

Pelli, D. G., Robson, J. G., \& Wilkins, A. J. (1988). The design of a new letter chart for measuring contrast sensitivity. Clinical Vision Sciences, 2, 187-199.

Pillias, C., Hsu, S, \& Cubaud, P. (2013). Reading with a digital roll. In W. E. Mackay, S. A. Brewster, \& S. Bødker (Eds.), CHI '13 Extended Abstracts on Human Factors in Computing Systems (pp. 1377-1382). New York: ACM. doi: 10.1145/2468356.2468602

Pölönen, M., Häkkinen, J., Jansson, D., Salmimaa, M., \& Kimmel, J. (2008). P-38: Flexible displays: Cognitive performance studies. In SID Symposium Digest of Technical Papers (pp. 1320-1323. doi: 10.1889/1.3069386

Rashbass, C., \& Westheimer, G. (1961). Disjunctive eye movements. The Journal of Physiology, 159, 339-360.

Rayner, K. (2009). Eye movements and attention in reading, scene perception, and visual search. The Quarterly Journal of Experimental Psychology, 62(8), 1457-1506. doi: $10.1080 / 17470210902816461$ 
VISUAL PERFORMANCE WITH CURVED DISPLAYS

1 Rosinski, R. R., Mulholland, T., Degelman, D., \& Farber, J. (1980). Picture perception: An analysis of visual compensation. Perception and Psychophysics, 28(6), 521-526. doi: $10.3758 / \mathrm{BF} 03198820$

Roufs, J. A. J., \& Boschman, M. C. (1997). Text quality metrics for visual display units: I. Methodological aspects, Displays, 18, 37-43.

Roudaut, A., Karnik, A., Löchtefeld, M., \& Subramanian, S. (2013). Morphees: Toward high "shape resolution" in self-actuated flexible mobile devices In W. E. Mackay, S. A. Brewster, \& S. Bødker (Eds.), CHI'13 Proceedings of the SIGCHI Conference on Human Factors in Computing Systems(pp. 593-602). New York: ACM. doi: $10.1145 / 2470654.2470738$

Rovamo, J., Virsu, V., \& Näsänen, R. (1978, January 5). Cortical magnification factor predicts the photopic contrast sensitivity of peripheral vision. Nature, 271, 54-56. doi: $10.1038 / 271054 \mathrm{a} 0$

Schwesig, C., Poupyrev, I., \& Mori, E. (2004). Gummi: A bendable computer. In E. DykstraErickson \& M. Tscheligi (Eds.), CHI '04 Proceedings of the SIGCHI Conference on Human Factors in Computing Systems (pp. 263-270). New York: ACM. doi: $10.1145 / 985692.985726$

Scialfa, C. T., \& Joffe, K. M. (1998). Response times and eye movements in feature and conjunction search as a function of target eccentricity. Perception \& Psychophysics, 60(6), 1067-82. doi: 10.3758/BF03211940

Singh, R., Unni, N. K. N., Solanki, A, \& Deepak (2012). Improving the contrast ratio of OLED displays: An analysis of various techniques. Optical Materials, 34, 716-723. doi: 10.1016/j.optmat.2011.10.005

Snijders, T., \& Bosker, R. (1999). Multilevel analysis. Thousand Oaks, CA: Sage. 
VISUAL PERFORMANCE WITH CURVED DISPLAYS

1 Stanislaw, H., \& Todorov, N. (1999). Calculation of signal detection theory measures. Behavior Research Methods, Instruments, \& Computers, 31, 137-149. doi: 10.3758/BF03207704

Vertegaal, R. \& Poupyrev, I. (2008). Organic user interfaces. Communications of the ACM, 51(6), 26-30. doi: 10.1145/1349026.1349033

Vishwanath, D., Girshick, A. R., Banks, M. S. (2005). Why pictures look right when viewed from the wrong place. Nature Neuroscience, 8(10), 1401-1409. doi:10.1038/nn1553

Wallach, H., \& Marshall, F. J. (1986). Shape constancy in pictorial representation. Perception and Psycholphysics, 39(4), 233-235. doi: 10.3758/BF03204929

Wang, A.-H., Tseng, C.-C., \& Jeng, S.-C. (2007). Effects of bending curvature and text/background color-combinations of e-paper on subjects' visual performance and subjective preferences under various ambient illuminance conditions. Displays, 28, 161166. doi: 10.1016/j.displa.2007.06.003

Wang, B., \& Ciuffreda, K. J. (2006). Depth-of-focus of the human eye: Theory and clinical implications. Survey of Ophthalmology, 51(1), 75-85. doi: 10.1016/j.survophthal.2005.11.003

Wetherill, G. B., \& Levitt, H. (1965). Sequential estimation of points on a psychometric function. The British Journal of Mathematical and Statistical Psychology, 18, 1-10. doi: 10.1111/j.2044-8317.1965.tb00689.x

Wightman, D., Ginn, T., \& Vertegaal, R. (2011). BendFlip: Examining input techniques for electronic book readers with flexible form factors. In P. Compos, N. Nunes, N. Graham, J. Jorge, \& P. Palanque (Eds.), INTERACT'11 Proceedings of the 13th IFIP TC 13 international conference on Human-computer interaction - Volume Part III (pp. 117133). Berlin: Springer-Verlag. 
VISUAL PERFORMANCE WITH CURVED DISPLAYS

1 Wolfe, J. M., \& Horowitz, T. S. (2004). What attributes guide the deployment of visual

2

3

4 5

6

7

8 Terhi Mustonen is a Doctoral student at Institute of Behavioural Sciences in University of

9 Helsinki. She obtained her M.A. in psychology from University of Helsinki in 2004.

10 Jyrki Kimmel is a Distinguished Researcher at Nokia Labs in Tampere, Finland. He obtained

11 his D. Sc. (Tech.) degree from Tampere University of Technology in 2012.

12 Jussi Hakala is a Doctoral student at the Department of Media Technology in Aalto

13 University, where he obtained his master's degree in media technology in 2010.

14 Jukka Häkkinen is a Principal investigator at Institute of Behavioural Sciences, University of

15 Helsinki. He obtained his PhD in psychology from University of Helsinki in 2007. 
$1 \quad$ Table 1

2 Local curvature effects in Experiment 2

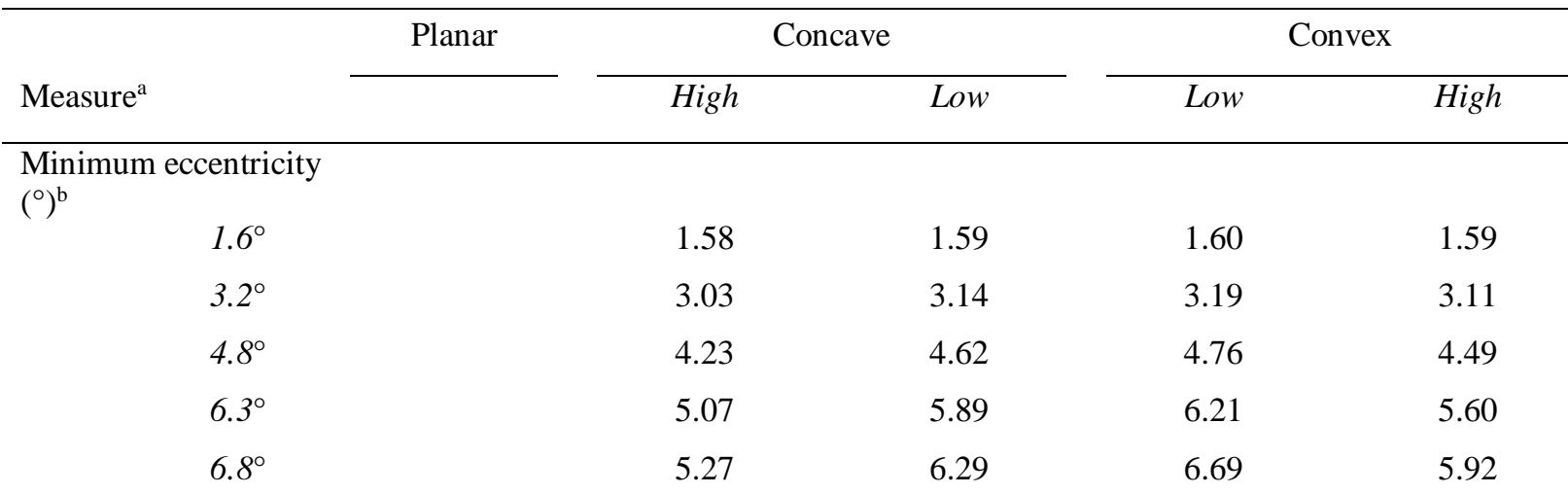

Target slant $\left({ }^{\circ}\right)$

$M \pm S E M$

$1.6^{\circ}$
$3.2^{\circ}$
$4.8^{\circ}$
$6.3^{\circ}$
$6.8^{\circ}$

$$
\begin{gathered}
9.44 \pm 1.43 \\
18.21 \pm 2.83 \\
36.80 \pm 1.85 \\
50.04 \\
52.86
\end{gathered}
$$$$
.72 \pm .71
$$$$
4.72 \pm .71
$$$$
9.44 \pm 1.43
$$$$
9.10 \pm 1.41
$$

$9.10 \pm 1.41$

$18.21 \pm 2.83$

$18.40 \pm 0.93$

$18.40 \pm 0.93$

$36.80 \pm 1.85$

25.02

25.02

50.04

26.43

26.43

52.86

Target height (') $M \pm S E M$

$\begin{array}{ll}1.6^{\circ} & 25.36 \\ 3.2^{\circ} & 25.33 \\ 4.8^{\circ} & 25.24 \\ 6.3^{\circ} & 25.13 \\ 6.8^{\circ} & 25.11\end{array}$

$$
\begin{gathered}
25.07 \pm .07 \\
24.24 \pm .24 \\
21.66 \pm 1.37 \\
18.62 \\
17.83
\end{gathered}
$$$$
25.32 \pm .01
$$$$
25.18 \pm .04
$$$$
24.79 \pm .13
$$$$
25.19 \pm .04
$$$$
24.67 \pm .15
$$$$
23.25 \pm .45
$$$$
24.79 \pm .06
$$$$
23.11 \pm .22
$$$$
18.75 \pm .61
$$

24.31

21.37

14.04

24.18

20.94

12.94

Viewing angle $\left({ }^{\circ}\right)^{\mathrm{b}}$

$1.6^{\circ}$
$3.2^{\circ}$
$4.8^{\circ}$
$6.3^{\circ}$
$6.8^{\circ}$

15.98

8.79

5.60

12.81

31.86

17.56

11.23

25.72

47.53

26.27

16.89

38.81

61.99

34.35

22.25

51.33

66.76

37.03

24.06

55.57

Brightness $(\%)^{\mathrm{b}}$

$\begin{array}{cc}1.6^{\circ} & 99 \\ 3.2^{\circ} & 99 \\ 4.8^{\circ} & 100 \\ 6.3^{\circ} & 99 \\ 6.8^{\circ} & 99\end{array}$

White point deviation $\left(\Delta u^{\prime} ; \Delta v^{\prime}\right)^{\mathrm{b}}$

$$
1.6^{\circ}-.002 ; .000
$$

$.000 ; .004$

$-.001 ; .001$

$.000 ; 000$

$-.003 ; .000$ 
VISUAL PERFORMANCE WITH CURVED DISPLAYS

$\begin{array}{cccccc}3.2^{\circ} & -.001 ; .000 & .009 ; .002 & .006 ; .003 & .000 ; 002 & .001 ; .006 \\ 4.8^{\circ} & -.001 ;-.001 & .031 ;-.007 & .009 ; .002 & .002 ; .003 & .014 ;-.002 \\ 6.3^{\circ} & .001 ; .001 & \mathrm{n} / \mathrm{a} & .015 ;-.001 & .001 ; .004 & \mathrm{n} / \mathrm{a} \\ 6.8^{\circ} & -.001 ; .001 & \mathrm{n} / \mathrm{a} & .021 ;-.003 & .003 ; .005 & \mathrm{n} / \mathrm{a}\end{array}$

1 Note. High $= \pm 50 \mathrm{~mm}$ radius curvature; Low $= \pm 100 \mathrm{~mm}$ radius curvature. ${ }^{\mathrm{a}}$ At standard

2 eccentricities $\left(1.6^{\circ}-6.8^{\circ}\right)$ defined with the planar display. ${ }^{b}$ Defined at display's vertical

3 midline, where the largest changes occur. ${ }^{c}$ Outside the measurement range $\left[-50^{\circ}, 50^{\circ}\right]$. 
$1 \quad$ Table 2

$2 \quad$ Local curvature effects in Experiment 3

\begin{tabular}{|c|c|c|c|c|c|c|}
\hline \multirow{2}{*}{ Measure } & & \multirow[t]{2}{*}{ Planar } & \multicolumn{2}{|c|}{ Concave } & \multicolumn{2}{|c|}{ Convex } \\
\hline & & & High & Low & Low & High \\
\hline \multicolumn{7}{|c|}{$\begin{array}{l}\text { Minimum eccentricity } \\
\left({ }^{\circ}\right)^{\mathrm{b}}\end{array}$} \\
\hline & $1.6^{\circ}$ & & 1.58 & 1.59 & 1.60 & 1.59 \\
\hline & $5.3^{\circ}$ & & 4.54 & 5.05 & 5.25 & 4.89 \\
\hline & $5.9^{\circ}$ & & 4.87 & 5.56 & 5.83 & 5.33 \\
\hline & $6.6^{\circ}$ & & 5.19 & 6.13 & 6.50 & 5.79 \\
\hline \multicolumn{7}{|c|}{$\begin{array}{l}\text { Target slant }\left(^{\circ}\right) \\
M \pm S E M\end{array}$} \\
\hline & $1.6^{\circ}$ & & $9.43 \pm 1.33$ & $4.72 \pm .66$ & $4.72 \pm .66$ & $9.43 \pm 1.33$ \\
\hline & $5.3^{\circ}$ & & $43.75 \pm .83$ & $21.88 \pm .42$ & $21.88 \pm .42$ & $43.75 \pm .83$ \\
\hline & $5.9^{\circ}$ & & $45.20 \pm .58$ & $22.60 \pm .29$ & $22.60 \pm .29$ & $45.20 \pm .58$ \\
\hline & $6.6^{\circ}$ & & $51.80 \pm .67$ & $25.90 \pm .33$ & $25.90 \pm .33$ & $51.80 \pm .67$ \\
\hline \multicolumn{7}{|c|}{$\begin{array}{l}\text { Target height }(') \\
M \pm S E M\end{array}$} \\
\hline & $1.6^{\circ}$ & & $16.72 \pm .04$ & $16.88 \pm .01$ & $16.79 \pm .03$ & $16.53 \pm .08$ \\
\hline & $5.3^{\circ}$ & & $13.45 \pm .13$ & $16.37 \pm .02$ & $14.83 \pm .07$ & $10.92 \pm .02$ \\
\hline & $5.9^{\circ}$ & & $13.23 \pm .09$ & $16.34 \pm .01$ & $14.71 \pm .05$ & $10.58 \pm .14$ \\
\hline & $6.6^{\circ}$ & & $12.08 \pm .12$ & $16.15 \pm .02$ & $14.07 \pm .07$ & $8.90 \pm .18$ \\
\hline \multicolumn{7}{|c|}{ Viewing angle $\left({ }^{\circ}\right)^{\mathrm{b}}$} \\
\hline & $1.6^{\circ}$ & & 15.98 & 8.79 & 5.60 & 12.81 \\
\hline & $5.3^{\circ}$ & & 52.38 & 28.97 & 18.67 & 42.95 \\
\hline & $5.9^{\circ}$ & & 58.16 & 32.2 & 20.82 & 47.96 \\
\hline & $6.6^{\circ}$ & & 64.86 & 35.96 & 23.33 & 53.87 \\
\hline \multicolumn{7}{|c|}{ Brightness $(\%)^{\mathrm{b}}$} \\
\hline & $1.6^{\circ}$ & 99 & 100 & 100 & 100 & 100 \\
\hline & $5.3^{\circ}$ & 100 & $\mathrm{n} / \mathrm{a}^{\mathrm{c}}$ & 94 & 99 & 73 \\
\hline & $5.9^{\circ}$ & 100 & $\mathrm{n} / \mathrm{a}$ & 91 & 99 & 65 \\
\hline & $6.6^{\circ}$ & 99 & $\mathrm{n} / \mathrm{a}$ & 85 & 97 & $\mathrm{n} / \mathrm{a}$ \\
\hline \multicolumn{7}{|c|}{$\begin{array}{l}\text { White point deviation } \\
\left(\Delta u^{\prime} ; \Delta v^{\prime}\right)^{\mathrm{b}}\end{array}$} \\
\hline & $1.6^{\circ}$ & $-.002 ; .000$ & $.000 ; .004$ & $-.001 ; .001$ & $.000 ; .000$ & $-.003 ; .000$ \\
\hline & $5.3^{\circ}$ & $-.001 ; .000$ & $\mathrm{n} / \mathrm{a}$ & $.01 ; .001$ & $.001 ; .004$ & $.017 ;-.006$ \\
\hline & $5.9^{\circ}$ & $.001 ;-.001$ & $\mathrm{n} / \mathrm{a}$ & $.016 ;-.001$ & $.002 ; .003$ & $.028 ;-.011$ \\
\hline & $6.6^{\circ}$ & $-.001 ; .001$ & $\mathrm{n} / \mathrm{a}$ & $.017 ;-.002$ & $.003 ; .003$ & $\mathrm{n} / \mathrm{a}$ \\
\hline
\end{tabular}


VISUAL PERFORMANCE WITH CURVED DISPLAYS

1 Note. High $= \pm 50 \mathrm{~mm}$ radius curvature; Low $= \pm 100 \mathrm{~mm}$ radius curvature. ${ }^{\mathrm{a}}$ At standard

2 eccentricities $\left(1.6^{\circ}-6.6^{\circ}\right)$ defined with the planar display. ${ }^{b}$ Defined at display's vertical

3 midline, where the largest changes occur. ${ }^{c}$ Outside the measurement range $\left[-50^{\circ}, 50^{\circ}\right]$. 


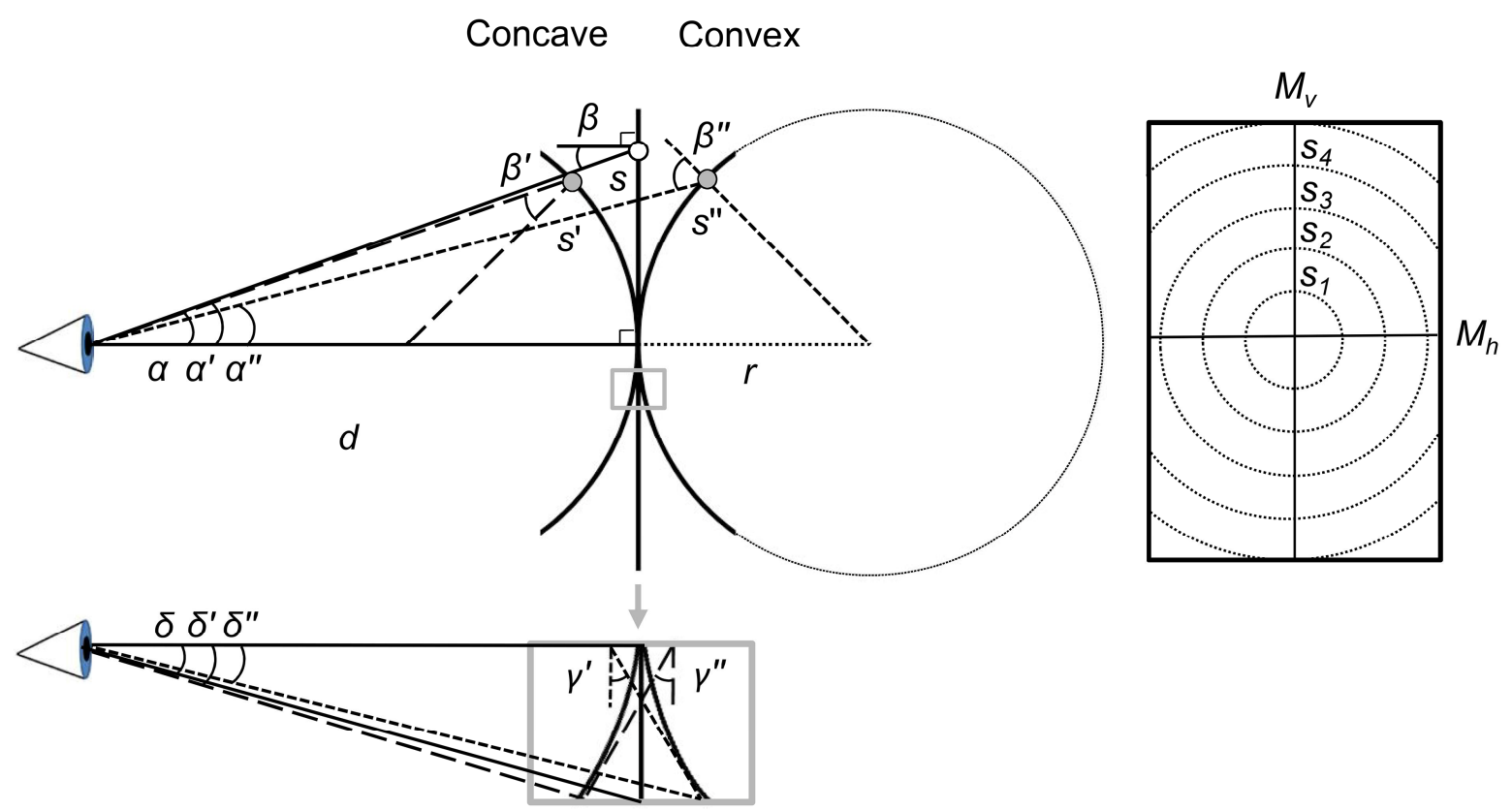

$1 \quad$ Figure 1

2 Display geometry with curved displays. Differences between concave and convex displays

3 that are curved about the horizontal axis and a planar surface from a constant viewing

4 distance $(d)$. The depth change is in the opposite direction in regard to concave (-) and convex

5 (+) displays. Radius curvature $(r)$ corresponds to the radius of a circle that best fits the curved

6 surface, and a small $r$-value, thus, indicates high curvature magnitude. The viewing angle for

7 a given point on display surface $(\beta)$ changes when the display is bent $(\beta$ ', $\beta$ '’). Similarly,

8 although an object's distance from the display center $(s)$ remains the same with curved

9 displays $\left(s^{\prime}, s^{\prime \prime}\right)$, its eccentricity $(\alpha)$ in the retinal representation decreases $\left(\alpha^{\prime}, \alpha^{\prime \prime}\right)$. In regard

to stimuli that are presented equidistant from the center at predetermined distances $\left(s_{1}, s_{2}\right.$,

$\left.11 s_{3} \ldots\right)$, the curvature-induced eccentricity change is largest at the vertical midline of the display

$12\left(M_{v}\right)$. In contrast, no noticeable changes occur at the horizontal midline $\left(M_{h}\right)$. Local changes in

13 surface orientation result in the slanting of objects with concave $\left(\gamma^{\prime}\right)$ and convex $\left(\gamma^{\prime \prime}\right)$

14 displays. This orientation change when combined with the depth variation modifies the retinal

15 size of the objects $\left(\delta^{\prime}, \delta^{\prime}\right)$, when compared to the planar display $(\delta)$. 


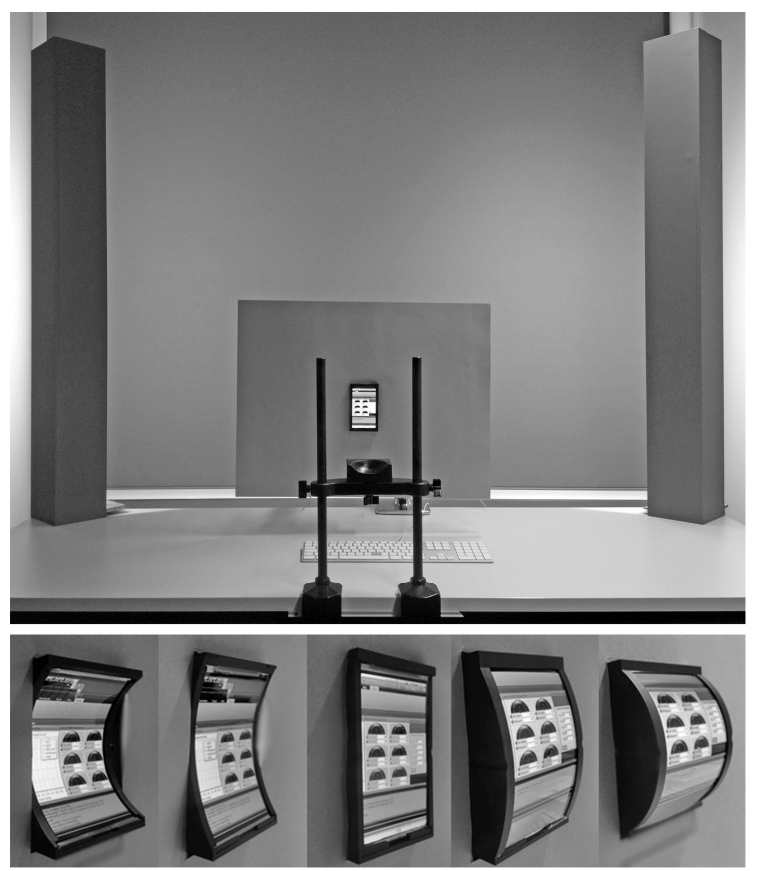

$1 \quad$ Figure 2

2 Experimental setup and display curvatures. Curvatures from left to right are high concave ( $r=$

$3-50 \mathrm{~mm})$, low concave $(r=-100 \mathrm{~mm})$, planar, low convex $(r=100 \mathrm{~mm})$, and high convex $(r=$ $450 \mathrm{~mm})$. 


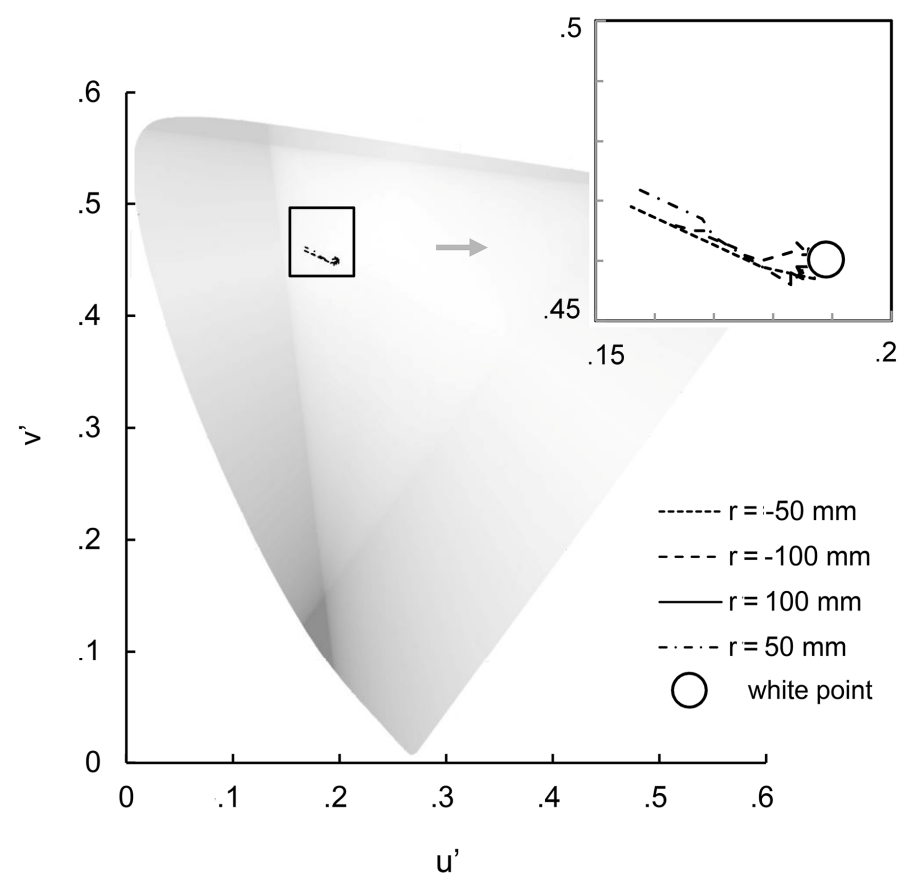

$1 \quad$ Figure 3

2 White point variation in curved displays (CIE 1976 coordinate). Increasing curvature

3 magnitude and eccentricity enlarges the viewing angle, which, in turn, shifts the white point

4 towards the green primary. 

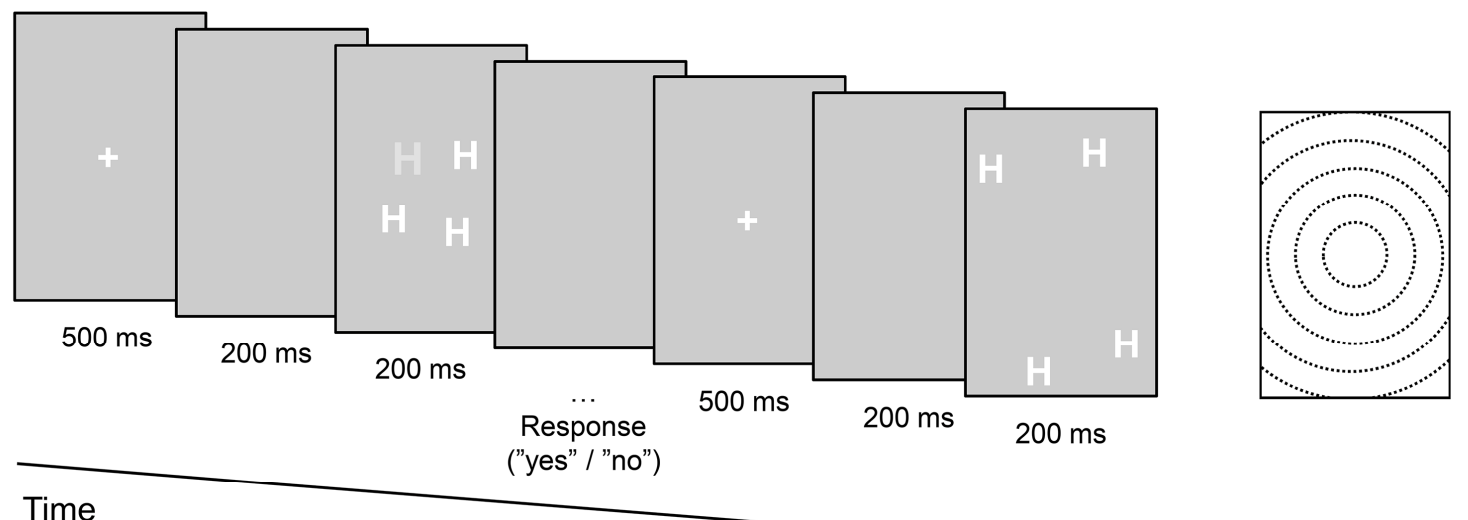

Time

\section{$1 \quad$ Figure 4}

2 Contrast-based target detection task (Experiments 1 and 2). Grey sequence (left) illustrates

3 display events during two consecutive trials. The subjects' task was to decide whether a target

4 (i.e., letter with lower contrast) appeared among the distracters (i.e., otherwise identical

5 letters) or not. White display (right) illustrates the eccentricities $\left(1.6^{\circ}, 3.2^{\circ}, 4.8^{\circ}, 6.3^{\circ}\right.$, and

$\left.6 \quad 6.8^{\circ}\right)$ at which letters were presented. 

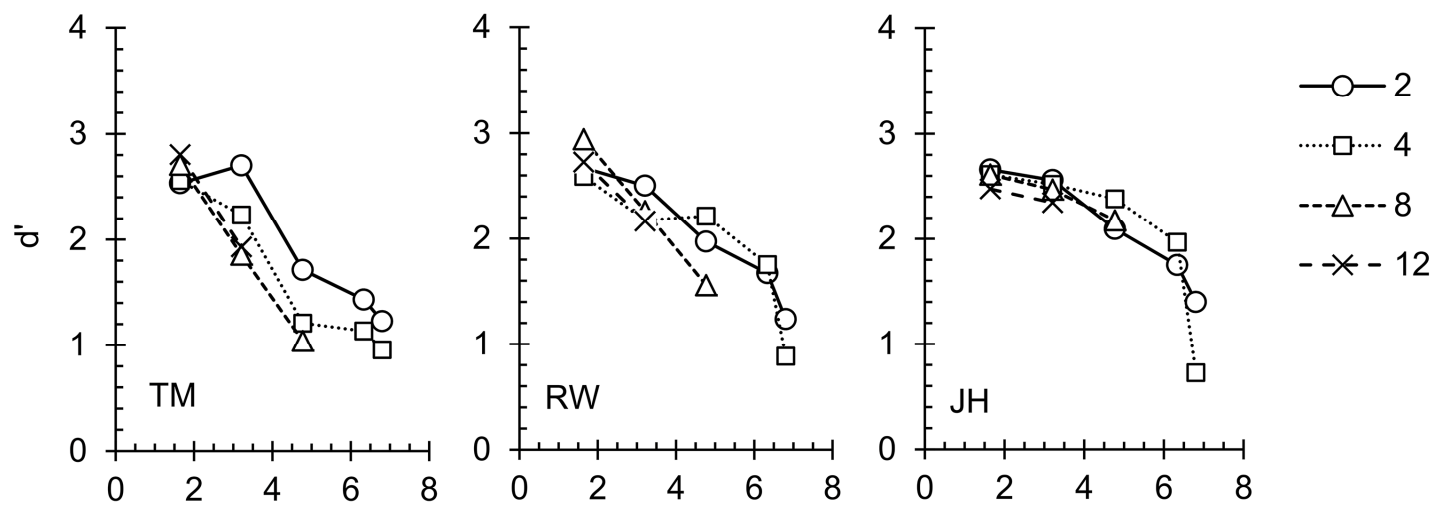

Eccentricity (deg)

\section{$1 \quad$ Figure 5}

2 Sensitivity of target detection ( $d^{\prime}$ ) with the planar display (Experiment 1 ). The figure plots

3 sensitivities as a function of eccentricity (measured at $1.6^{\circ}, 3.2^{\circ}, 4.8^{\circ}, 6.3^{\circ}$, and $6.8^{\circ}$ ) with

4 four set sizes $(2,4,8$, and 12). The results for the three subjects (TM, RW, and JH) are

5 depicted in different panels. Each data point is based on 240 trials. 


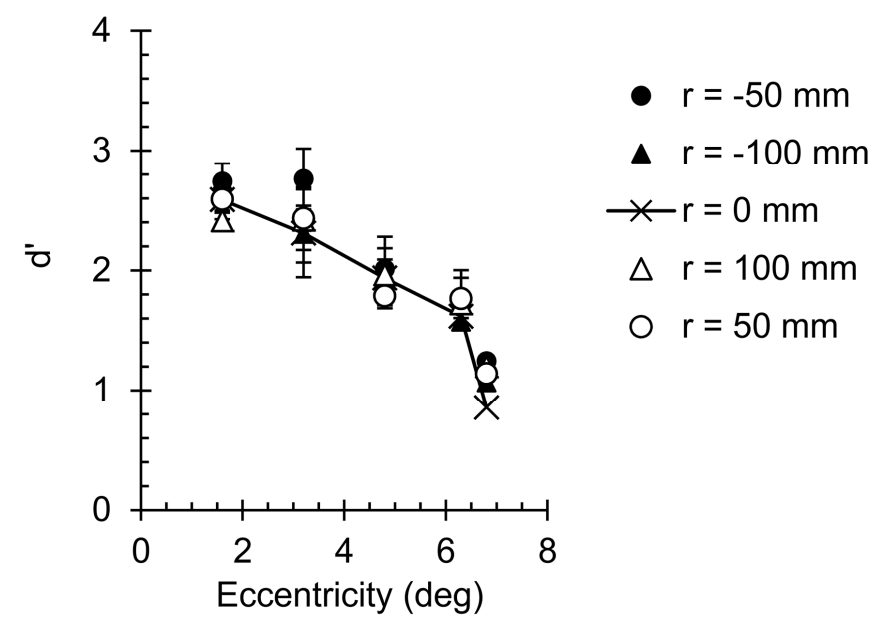

\section{$1 \quad$ Figure 6}

2 Sensitivity in contrast-based target detection ( $d$ ') with curved displays (Experiment 2). Mean

$3(n=3)$ results are plotted as the function of eccentricity from the display center. A solid line

4 indicates performance with the planar display. Filled markers are concave curvatures, and

5 open markers are convex curvatures. Error bars represent the standard errors of the mean. 

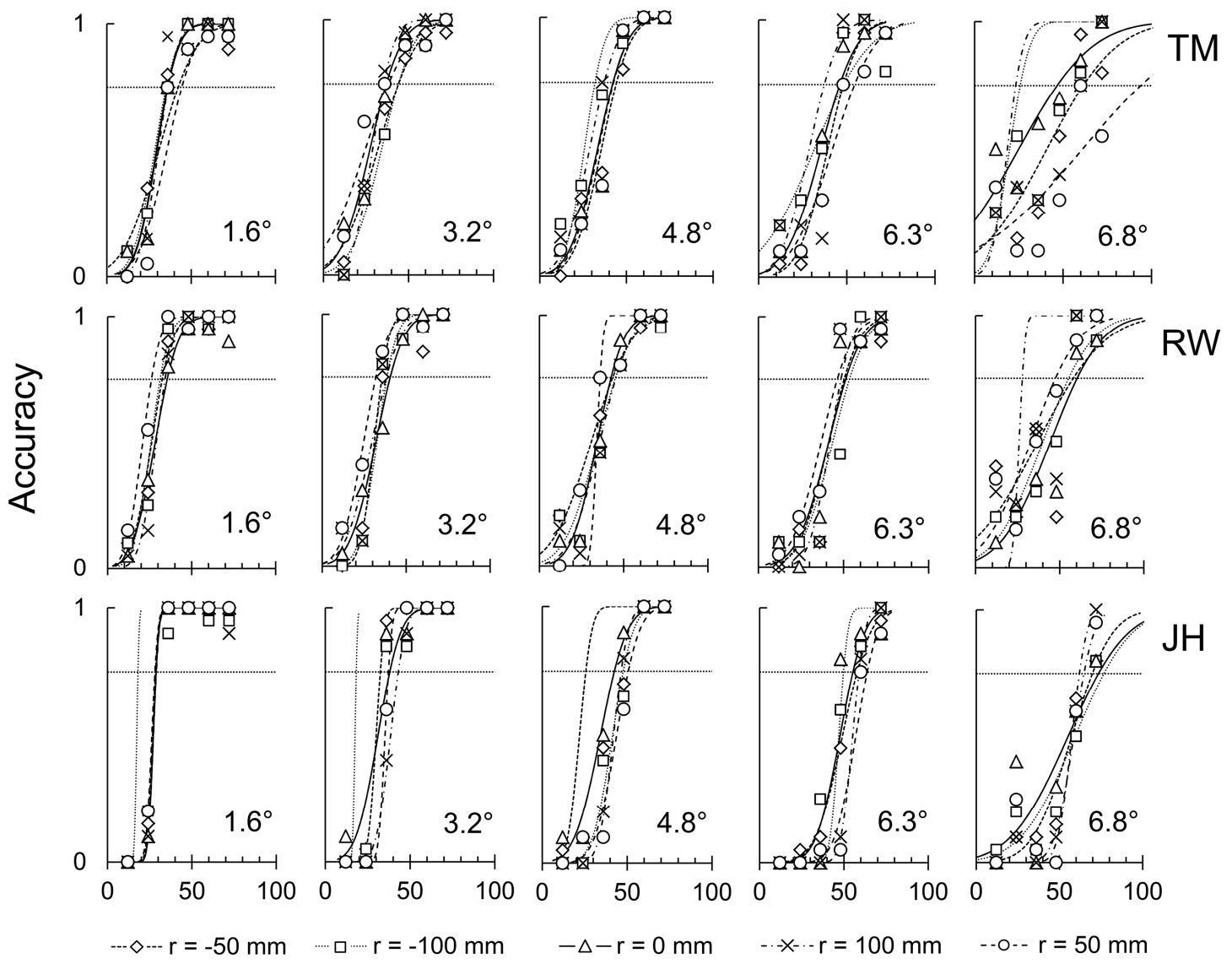

Contrast increment (\%)

\section{$1 \quad$ Figure 7}

2 Accuracy of target detection with curved displays (Experiment 2). The results are plotted as

3 the function of the target-distractor contrast for three subjects (TM, RW, JH) at five

4 eccentricities $\left(1.6-6.8^{\circ}\right)$, separately. Each data point is based on twenty repetitions. The

5 horizontal line indicates a 0.75 threshold. 

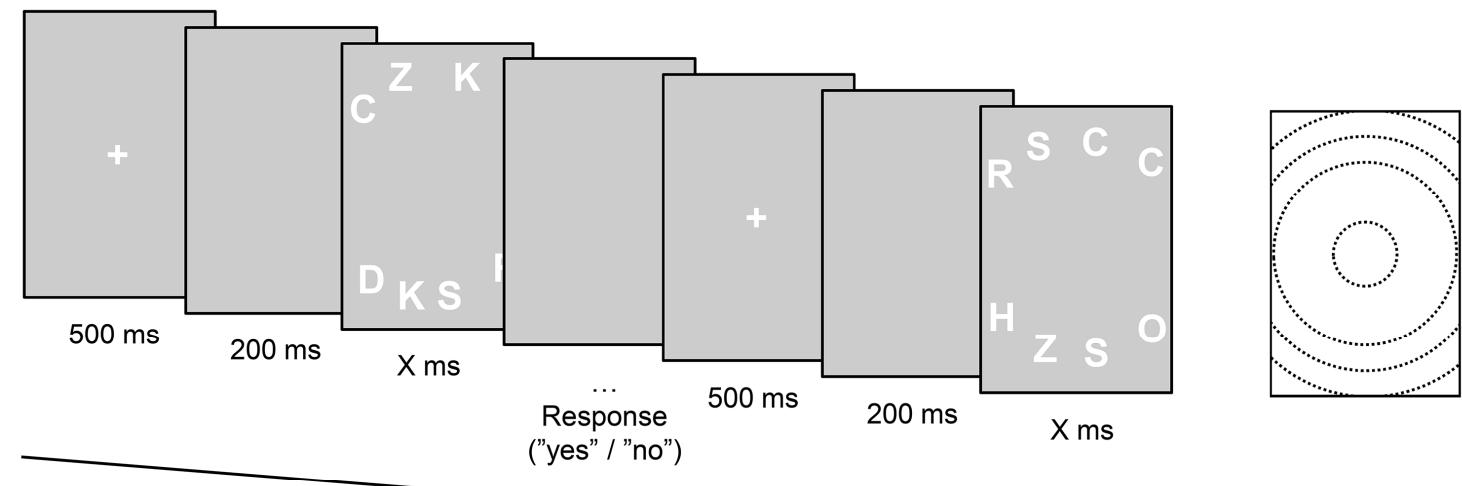

Time

$1 \quad$ Figure 8

2 Letter search task (Experiment 3). The grey sequence (left) illustrates display events during

3 two consecutive trials. The subjects' task was to decide whether a target letter (H) appeared

4 among the distracter letters. The presentation duration for the stimuli varied depending on the

5 subject's performance. The white display (right) illustrates the eccentricities $\left(1.6^{\circ}, 5.3^{\circ}, 5.9^{\circ}\right.$,

6 and $6.6^{\circ}$ ) at which the letters were presented. 


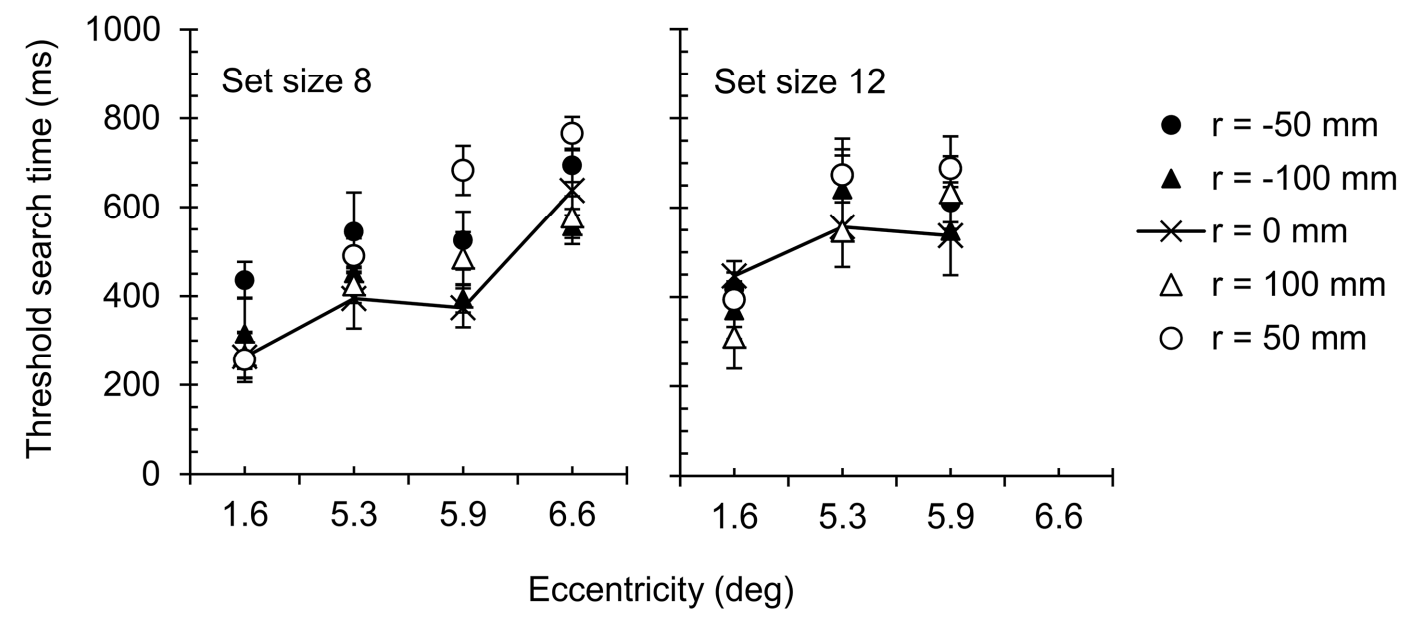

\section{$1 \quad$ Figure 9}

2 Threshold search times with curved displays (Experiment 3). Mean $(\mathrm{n}=8)$ results are plotted

3 as the function of eccentricity for two set sizes, separately. Solid lines indicate the thresholds

4 for the planar display. Filled markers indicate concave displays, and open markers indicate

5 convex displays. Error bars represent the standard errors of the mean. 


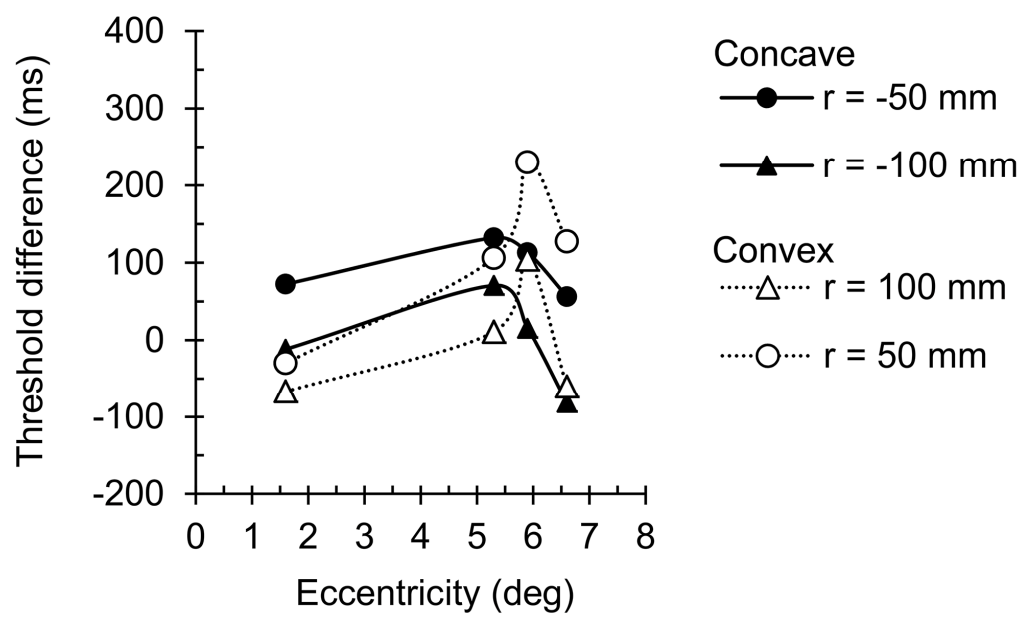

$1 \quad$ Figure 10

2 Effect of display curvature on threshold search times (Experiment 3). Performance with

3 concave and convex displays relative to the planar display $\left(\mathrm{D}_{\text {Curved }}-\mathrm{D}_{\text {Plane }}\right)$ is illustrated as

4 the function of eccentricity. The figure combines the data for the set sizes 8 and 12 illustrated

5 in Figure 9. Performance at the 0 level corresponds to performance for the planar display.

6 High positive values demonstrate large decrements. The results are calculated over the two set

7 sizes. Filled markers indicate concave curvatures, and open markers indicate convex

8 curvatures. Note that performance with low convex and low concave curvatures did not differ

9 from the performance for the planar display. 